\title{
The neuropathology of bipolar disorder: systematic review and meta-analysis
}

\author{
Paul J. Harrison $\mathbb{1}^{1,2} \cdot$ Lucy Colbourne ${ }^{1,2} \cdot$ Charlotte H. Harrison $\mathbb{(}^{3}$ \\ Received: 30 April 2018 / Revised: 16 July 2018 / Accepted: 24 July 2018 / Published online: 20 August 2018 \\ (c) The Author(s) 2018. This article is published with open access
}

\begin{abstract}
Various neuropathological findings have been reported in bipolar disorder (BD). However, it is unclear which findings are well established. To address this gap, we carried out a systematic review of the literature. We searched over 5000 publications, identifying 103 data papers, of which 81 were eligible for inclusion. Our main findings can be summarised as follows. First, most studies have relied on a limited number of brain collections, and have used relatively small sample sizes (averaging $12 \mathrm{BD}$ cases and 15 controls). Second, surprisingly few studies have attempted to replicate closely a previous one, precluding substantial meta-analyses, such that the latter were all limited to two studies each, and comprising 16-36 BD cases and 16-74 controls. As such, no neuropathological findings can be considered to have been established beyond reasonable doubt. Nevertheless, there are several replicated positive findings in BD, including decreased cortical thickness and glial density in subgenual anterior cingulate cortex, reduced neuronal density in some amygdalar nuclei, and decreased calbindin-positive neuron density in prefrontal cortex. Many other positive findings have also been reported, but with limited or contradictory evidence. As an important negative result, it can be concluded that gliosis is not a feature of BD; neither is there neuropathological evidence for an inflammatory process.
\end{abstract}

\section{Introduction}

Like other 'functional' psychiatric disorders, bipolar disorder (BD) lacks any diagnostic neuropathology of the kind which characterises and defines the dementias, but this does not mean that BD has no morphological correlates. Magnetic resonance imaging (MRI) studies show small but robust differences in the volumes of some brain structures, notably decreases in hippocampus, amygdala and thalamus, and reduced cortical thickness $[1,2]$. There is also increasing

Electronic supplementary material The online version of this article (https://doi.org/10.1038/s41380-018-0213-3) contains supplementary material, which is available to authorised users.

Paul J. Harrison

paul.harrison@psych.ox.ac.uk

1 Department of Psychiatry, University of Oxford, Warneford Hospital, Oxford OX3 7JX, UK

2 Oxford Health NHS Foundation Trust, Warneford Hospital, Oxford, UK

3 Faculty of Medicine, University of Southampton, Southampton General Hospital, Southampton, UK evidence for white matter decrements [3, 4] with anatomical and functional dysconnectivity of specific pathways and circuits [5, 6]. Presumably these neuroimaging findings are reflected in alterations at the histological and cellular level. However, a review covering the period up to 1999 noted the remarkable lack of data [7]. By the definition of neuropathology adopted here (see Methods and Materials), the literature at that time comprised only nine publications. Vawter and colleagues [7] drew attention to some preliminary findings, notably a report of decreased glial density in the subgenual anterior cingulate cortex (sgACC) in $\mathrm{BD}$ and major depressive disorder [8], and a pilot study describing decreased interneuron density in the hippocampal CA2 subfield [9].

Öngür et al. (1998) [8] remains by some distance the most cited paper on the neuropathology of BD (Supplementary Table 1), and it was soon followed by a series of other morphometric studies. Many took advantage of the brain series collected by the Stanley Foundation (subsequently the Stanley Medical Research Institute), called the Stanley Neuropathology Consortium [10]. For the first time, this provided brain tissue specifically designed to allow comparison of $\mathrm{BD}$, schizophrenia and major depressive disorder with healthy comparison subjects $(n=15$ in each group) [10]. Moreover, tissue was provided blind to 
diagnosis such that researchers had to include BD, even if their primary interest lay in one of the other diagnoses.

An updated narrative review of the neuropathology of mood disorder was reported by Harrison (2002) [11], by which time the BD literature extended to 27 papers. More recently, Price and Drevets (2010) [12] reviewed mood disorder neuropathology in the context of neuroimaging findings and normative brain connectivity, and Savitz et al. (2014) [13] focused on the prefrontal cortex. To our knowledge, there has been no substantive review covering BD neuropathology since then, and there has never been a systematic review. Here, we report the latter, accompanied by meta-analyses where possible. The review was registered on the PROSPERO international prospective register of systematic reviews (CRD42018089740).

\section{Methods and Materials}

\section{Scope of systematic review}

We adopted a pragmatic definition of neuropathology to comprise studies which measured 'visible' parameters such the density, number, size or shape of cells (neurons, glia or subpopulations thereof), cellular constituents (e.g. synapses, dendrites and mitochondria), or cytopathological elements (e.g. neurofibrillary tangles, amyloid plaques), in patients with BD compared to control subjects. We included studies which identified neuronal and glial populations using antigens generally recognised for this purpose (e.g. parvalbumin [PV], glial fibrillary acidic protein [GFAP], ionised calcium-binding adaptor molecule 1 [Iba-1]). We also included studies which measured the size of a brain structure (e.g. cortical thickness, hippocampal volume). We excluded studies which used messenger RNAs to delineate cell populations or which used proteins as proxy markers of sub-cellular compartments (e.g. synaptophysin as a marker of presynaptic terminals, or spinophilin for dendritic spines). We also excluded studies using brain homogenates.

\section{Literature search and data extraction}

We identified publications by searching the Web of Science Core Collection (1945 to 8th June 2018) and MEDLINE (1950 to $8^{\text {th }}$ June 2018) using the following search terms: ('bipolar disorder' or 'bipolar affective' or 'bipolar illness' or 'bipolar disease' or 'manic-depressi*' or 'manic depressi*') and ('neuropatholog*' or 'morphometr*' or 'neuron*' or 'glia*' or 'pyramidal' or 'oligodendro*' or 'astrocyt*' or 'astrogli*' or 'microgli*' or '*gliosis'). We also searched papers' reference lists and PJH's reprint collection to identify additional studies meeting our criteria. We did not consider papers including less than three BD cases, conference abstracts, non-peer reviewed publications (e.g. book chapters), nor data papers not published in English. Two authors (PJH, with either $\mathrm{LC}$ or $\mathrm{CHH}$ ) independently conducted the searches and the data extraction, and all authors met to resolve any divergent results. Graphical data were extracted using Webplotter (https://apps. automeris.io/wpd/).

We decided a priori to meta-analyse studies where at least two datasets were available, and which had measured the same parameter in the same brain region. In practice, this required judgement about what constituted metaanalysable data. Only data presented in the form of group means together with a measure of variance were considered for meta-analysis; this excluded several studies (e.g. which used medians and interquartile ranges). Meta-analyses were conducted with a fixed effects model, using Review Manager (RevMan) 5.3. Standardised mean differences (SMD) were used except where stated. Where necessary, standard errors were converted to standard deviations. If subgroups needed to be combined for meta-analysis (e.g. if a paper analysed males and females separately, or presented data for both right and left hemisphere), we used the formulae for weighted means and standard deviations in the Cochrane Handbook [14]. For studies reporting data for individual cortical layers or hippocampal subfields, a summary statistic for an overall diagnostic effect across all layers/subfields was also computed by RevMan; this statistic uses the number of observations not the number of subjects to calculate significance, and so should be interpreted with caution.

\section{Results}

The literature search found 5388 publications meeting our criteria, and an additional 15 papers were found from other sources. Of the 5403 papers, 103 were selected for detailed inspection based on the abstract. 81 proved to have eligible original data $[8,9,15-93]$, and form the focus of the systematic review. The 22 excluded papers are listed in Supplementary Table 2 together with the reason for their omission. The PRISMA diagram is shown as Supplementary Figure 1.

\section{Characteristics of included studies}

The basic demographics of the 81 studies are shown in Table 1.

Most studies utilised tissue from recognised brain collections, notably the Stanley Neuropathology Consortium ( $n=35$ studies), Harvard/McLean brain bank $(n=17)$, and Magdeburg brain collection $(n=11)$. The remainder came from a range of other sources; some studies used more than 
Table 1 Demographic characteristics of the 81 studies included in the systematic review

\begin{tabular}{llll}
\hline & Mean & SD & Range \\
\hline BD subjects per study $(n)^{\mathrm{a}}$ & 11.5 & 4.3 & $3-21$ \\
Females & 5.4 & 2.5 & $1-12$ \\
Males & 6.4 & 2.7 & $1-10$ \\
Controls per study $(n)^{\mathrm{a}, \mathrm{b}}$ & 14.8 & 7.0 & $3-55$ \\
Females & 6.3 & 4.0 & $1-33$ \\
Males & 8.7 & 3.6 & $2-24$ \\
Ages (years) & & & \\
BD & 50.6 & 9.7 & $27-74$ \\
Controls & 54.0 & 7.8 & $42-75$ \\
\hline
\end{tabular}

${ }^{\text {a }}$ Sex-specific information known for $n=78$ studies.

${ }^{\mathrm{b}}$ Excluding Shioya et al. [89]; see Table 6.

one series. Most studies used diagnostic criteria for BD: DSM-IV $(n=59)$, DSM-III-R $(n=13)$, and ICD-10 $(n=$ $4)$; the remaining studies used other criteria or did not specify. Reflecting the fact that the brain collections mentioned above also include schizophrenia and/or major depressive disorder, many studies also included one or both diagnostic groups (schizophrenia $[n=58]$, major depressive disorder $[n=57])$. In terms of anatomical focus, a range of brain regions have been studied: prefrontal cortex (PFC; $n$ $=19$ ), especially dorsolateral (DLPFC; $n=15$ ); ACC, including $\operatorname{sgACC}(n=17)$; other neocortical regions $(n=$ $10)$; hippocampus $(n=13)$; amygdala $(n=8)$; entorhinal cortex $(n=7)$; white matter $(n=10)$; thalamus $(n=6)$; other $(n=18)$. Fourteen studies included more than one region. We rated 28 studies as adhering broadly to stereological principles (e.g. random sampling, 3D counting), 24 did so partially, and 29 either did not or could not be rated. Sixty five studies were carried out blind to diagnosis; no information about blinding was given for 16 studies.

Results are discussed region by region, and summarised in Tables 2-6 and Supplementary Tables 3 and 4. The Tables highlight, for each study, the main results which the authors reported as being statistically significant, as well as important negative findings. Studies which we metaanalysed and their findings are described in the text, summarised in Supplementary Table 5, and illustrated in Figs. 1-4 and Supplementary Figures 2-7. In the event, only two datasets for any given parameter in any one brain region were amenable to meta-analysis.

\section{Anterior cingulate cortex (ACC)}

The ACC is an anatomically and functionally heterogeneous structure at the interface of cognition, emotion and behaviour [94-96]. It became of great interest in mood disorders after a study showing a focal decreased volume, and reduced metabolism, in the sgACC [97]. The same group then sought an anatomical correlate of these findings. They reported (in a pilot study and in a second, larger cohort) a reduction of glial density, using unbiased stereological methods on Nissl-stained sections, present in BD and in subjects with major depressive disorder [8]. Neuronal density and number were unchanged, and sgACC volume non-significantly reduced. Glial density was unaltered in the parietal cortex, suggesting a degree of anatomical localisation, and glial density was unchanged in the sgACC in schizophrenia, indicating a degree of diagnostic specificity.

Öngür et al. [8] was arguably the first significant neuropathological study of $\mathrm{BD}$, and the first to use contemporary methods. It has been followed by 16 further studies of ACC neuropathology in BD (Table 2); 4 include sgACC, 13 examined other parts of the ACC. However, there have been no direct replications of the design or methods used by Öngür et al., precluding any meta-analysis of their data beyond simply combining the two datasets in their original paper. This confirms the reduction in glial density in BD in sgACC, and also shows a borderline significant decrease in glial number, but no difference in sgACC volume (Fig. 1). The findings strengthen the conclusions drawn by Öngür and colleagues, not least since their paper used one-tailed tests for some analyses.

The largest BD ACC study is by Bouras et al. [26], who reported reduced neuronal density in layers III, V, and VI of sgACC. These laminae were also thinner than in controls, as was the grey matter as a whole. The changes were similar but less pronounced in schizophrenia, and not seen in major depression. They state that no differences between BD and controls were seen in occipital cortex, but do not present the data. Glia were not measured. In a much smaller study of sgACC, Sinka et al. [78], who only measured layers III and $\mathrm{V}$, found a non-significant trend towards decreased thickness of layer III, but no difference in neuronal density in BD in either lamina. Again, glia were not measured. Williams et al. [82] found a thinner grey matter in the $\operatorname{sgACC}$ crown in $\mathrm{BD}$, with a reduced layer $\mathrm{V}$ thickness in the right hemisphere. Meta-analysis of $\operatorname{sgACC}$ layer thickness using data from refs. 26 and 82 shows a decrease in layers III, V, and VI in BD (Fig. 2). In a companion paper, Williams et al. (2013b) [83] counted sgACC oligodendrocytes using a Nissl stain, and astrocytes using GFAP immunohistochemistry, and found no differences in BD.

Studies of the non-subgenual parts of ACC provide a mixed picture (Table 2). Bouras et al. [26] measured the same parameters as noted above in sgACC, and found no differences between $\mathrm{BD}$ and controls in the dorsal ACC. However, when their layer thickness data were metaanalysed together with Benes et al. [25], the trend reduction seen in both studies for a thinner layer $\mathrm{V}$ became significant (Supplementary Figure 2). 


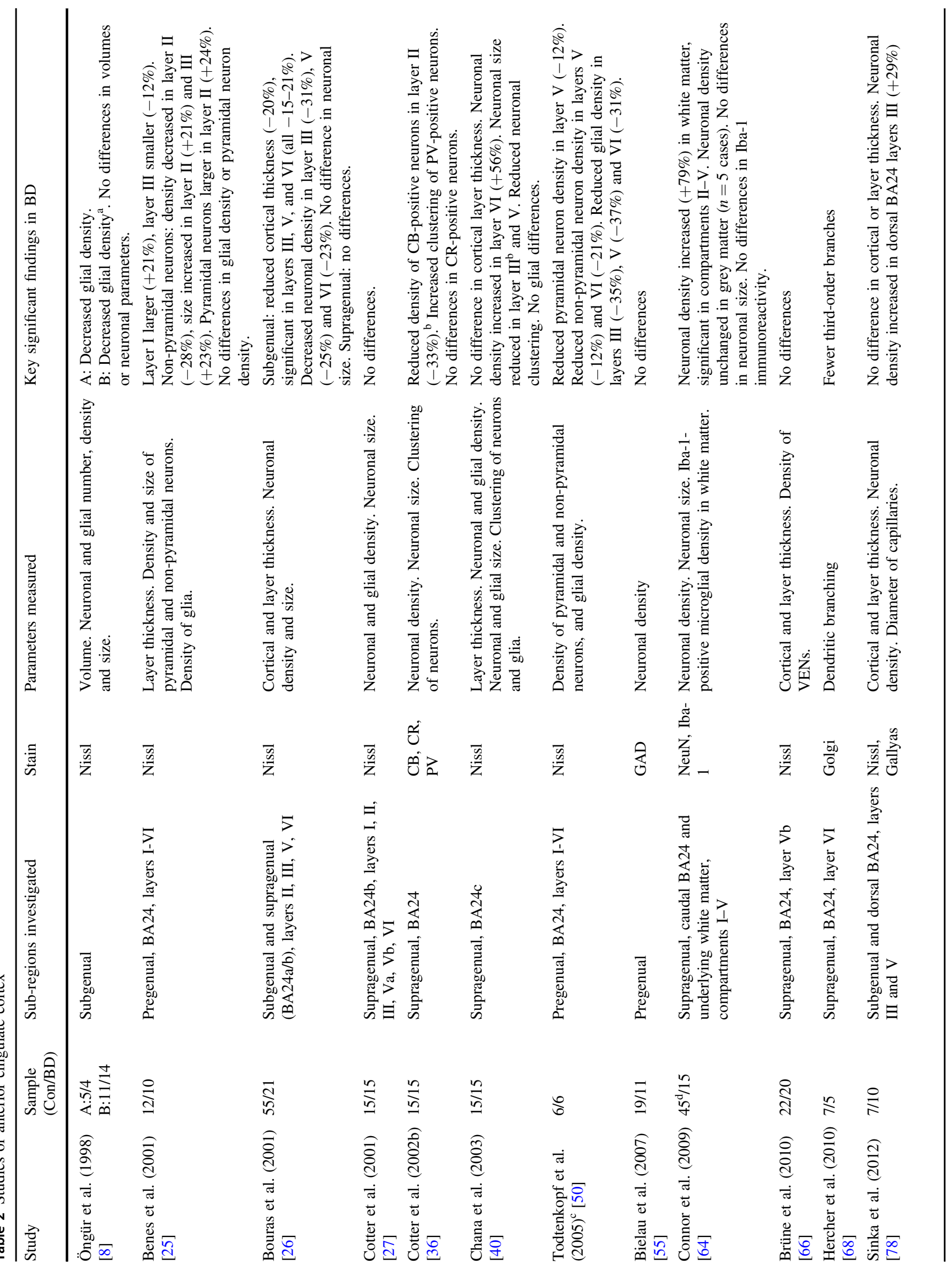




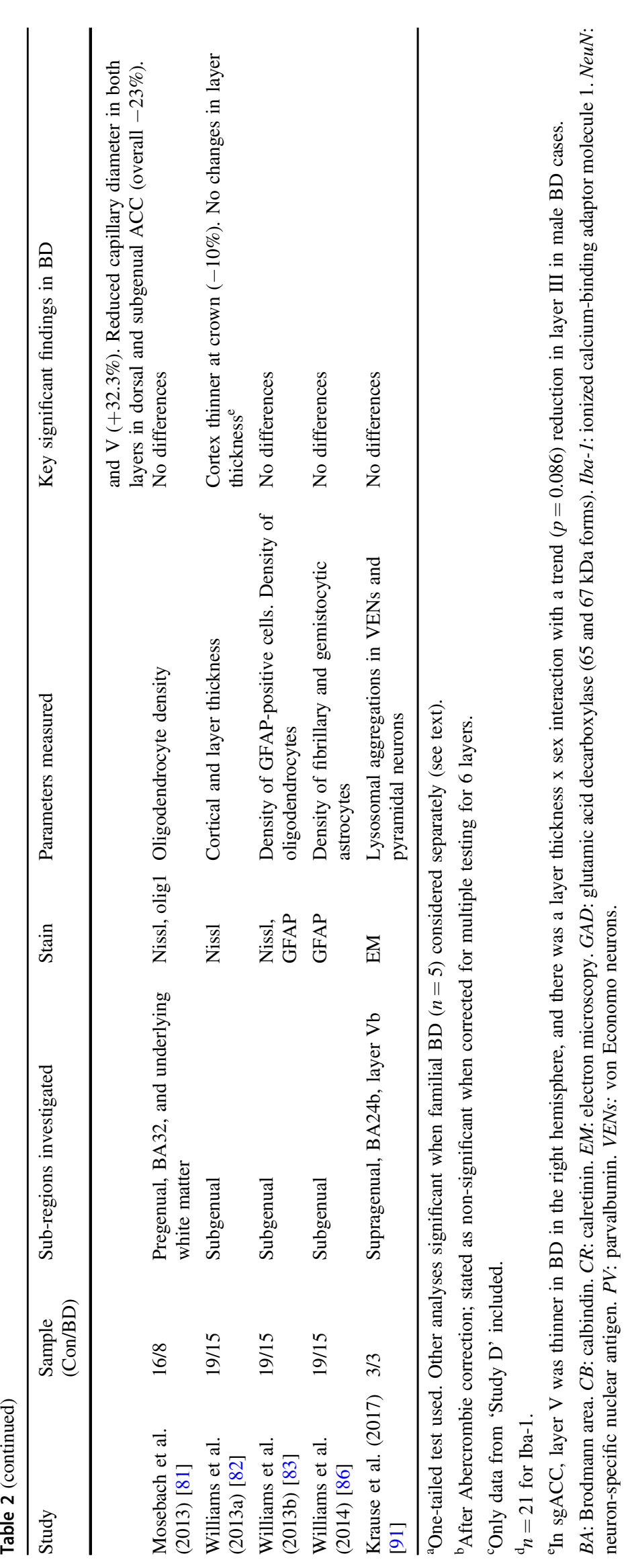




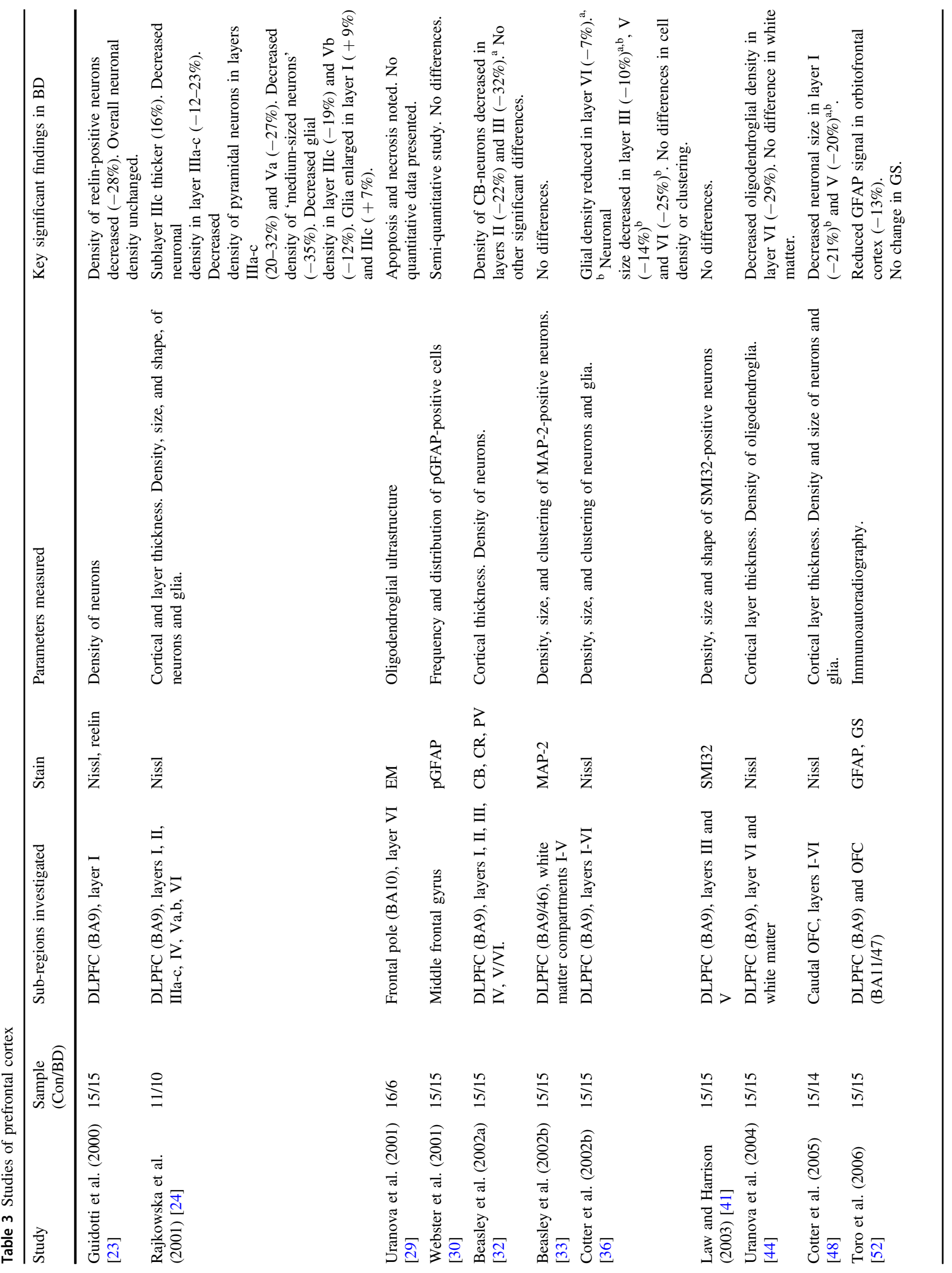




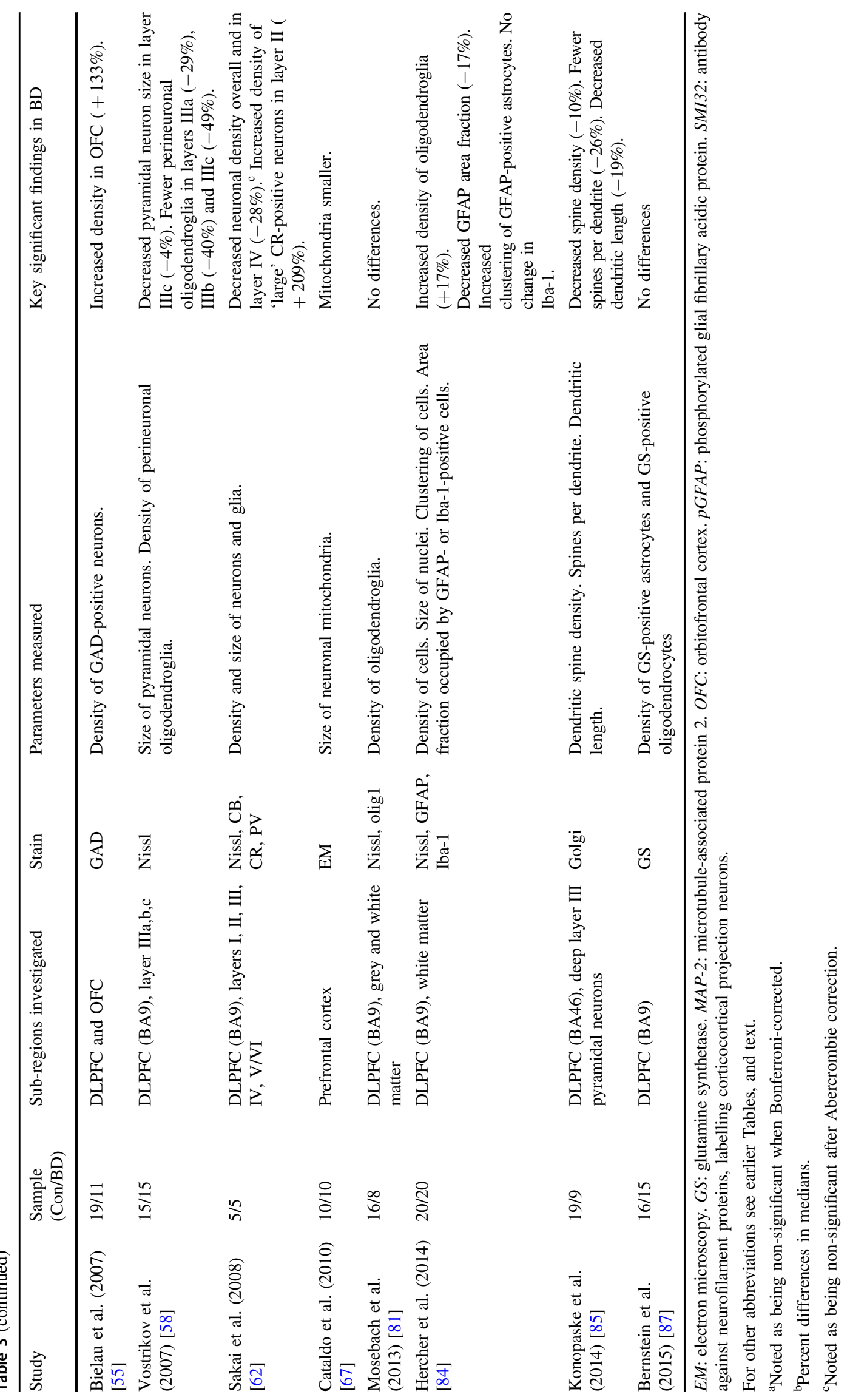


The main finding of Benes et al. [25], who studied the rostral ACC, was a marked reduction in the density of nonpyramidal neurons in layer II, which remained significant after Abercrombie correction for cell size. The latter point is relevant since the neurons were larger in $\mathrm{BD}$ than in controls. The authors found no differences in pyramidal neuron density, or in glial density, in BD. The same group later used a different (three-dimensional, stereological) counting method in a subset of the same brains, and found modest but significant reductions in the density of non-pyramidal and pyramidal neurons, and glia, in $\mathrm{BD}$, mostly in layer $\mathrm{V}$ [50]. In contrast, Cotter et al. [27] found no differences in glial density, neuronal density, or neuronal size in BD in the supra-callosal ACC (Brodmann area [BA] 24b) using a stereological approach. This group later used an adjacent part of the supragenual ACC (BA24c) of the same subjects for a two-dimensional study of density, size, and clustering of neurons and glia; in BD, neuronal size was decreased in layer V, and neuronal density increased in layer VI [40]. Neither study could be included in a meta-analysis because data were presented as medians [27] or as means but without any measure of variance [40].

Connor et al. [64] studied the white matter below the caudal ACC to study the density of white matter neurons (stained by NeuN) since altered distribution of these neurons in schizophrenia had been reported, and viewed as indicative of disordered neurodevelopment. In this relatively large study, they reported an increased density of ACC white matter neurons in $\mathrm{BD}$, with a similar finding in PFC white matter.

In summary, there have been intriguing findings in the sgACC in BD, notably the glial deficits identified by Öngür et al. [8] and a thinning of the cortex found in two independent studies $[26,82]$. In other regions of the ACC, the findings are less prominent and not well replicated for either glial or neuronal alterations, though there is moderate evidence for a thinner layer $\mathrm{V}$.

\section{Prefrontal cortex (PFC)}

The PFC has been the most studied brain region in BD. Virtually all studies have been carried out in the DLPFC (BA9 and 46). This neuropathological focus can be traced in part to the prominence of this region in studies of schizophrenia at the time when the Stanley Neuropathology Consortium tissue was being made available (see Introduction) $[98,99]$. There had also been emerging interest in cognitive aspects of $\mathrm{BD}$ which suggested potential involvement of the PFC $[100,101]$.

Neuropathological studies of PFC in BD are summarised in Table 3. The first report was by Guidotti et al. (2000) [23]. Amongst other parameters, they reported a marked decrease in the density of reelin-positive neurons in layer I (wherein 


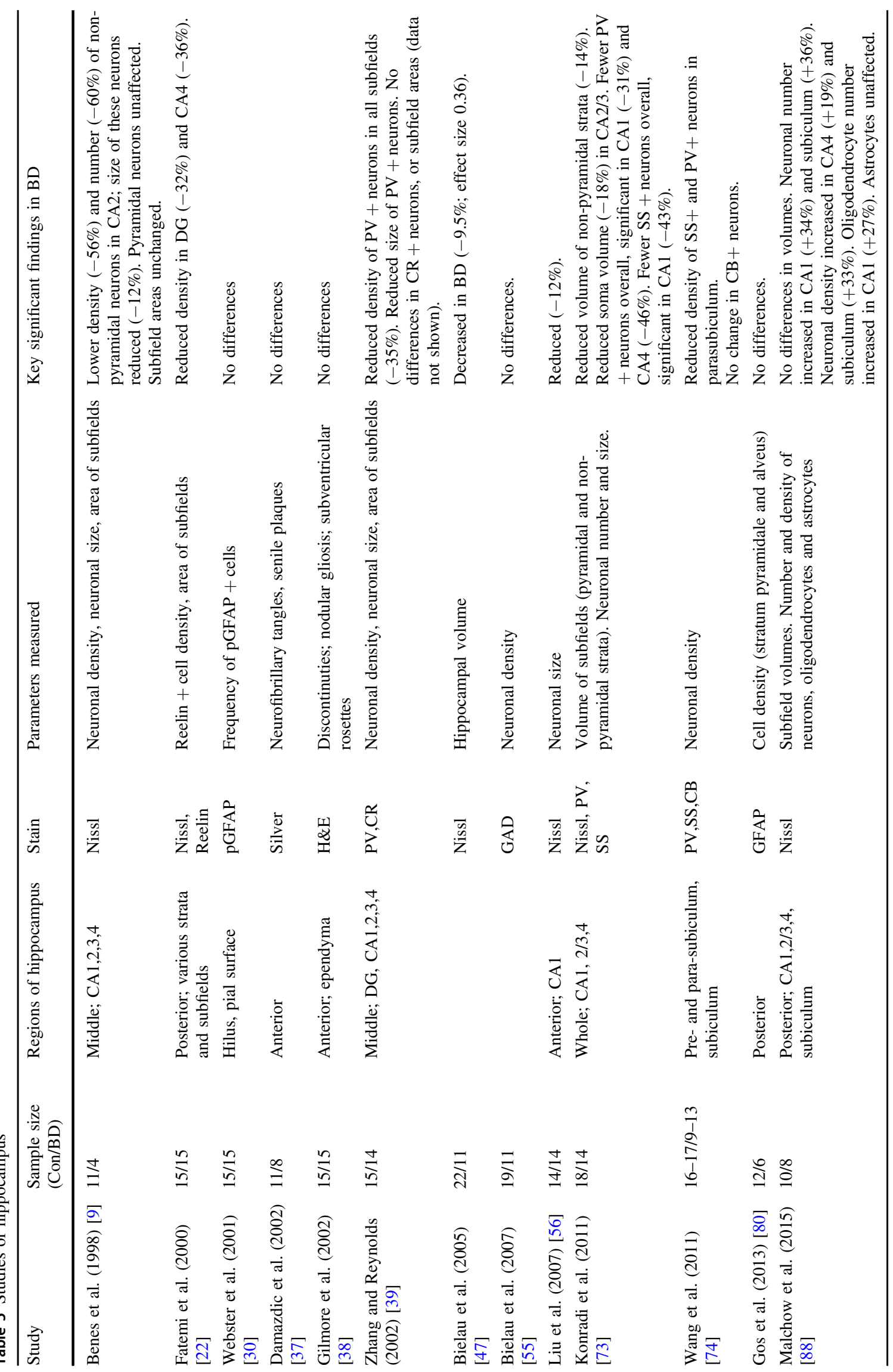




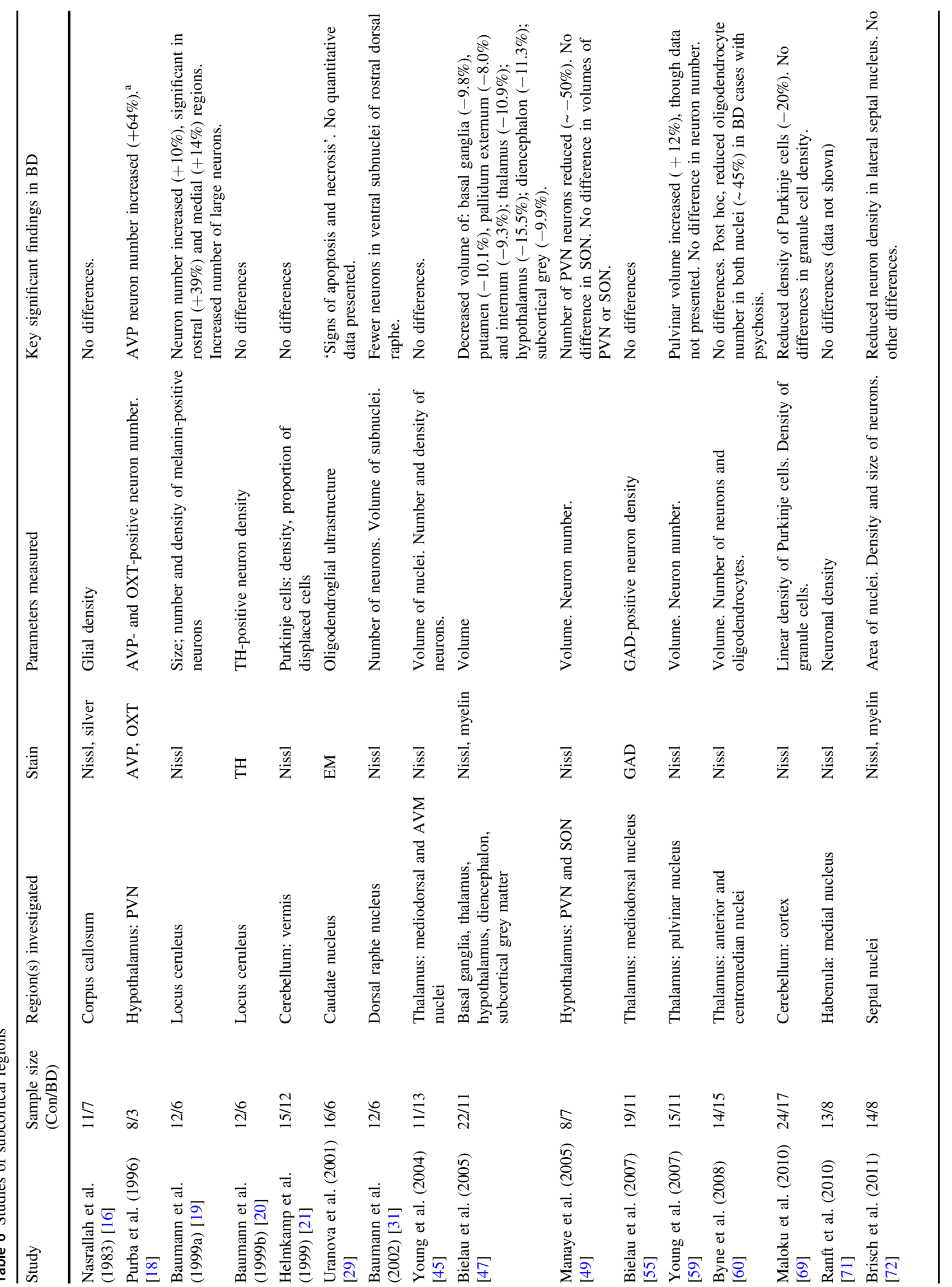




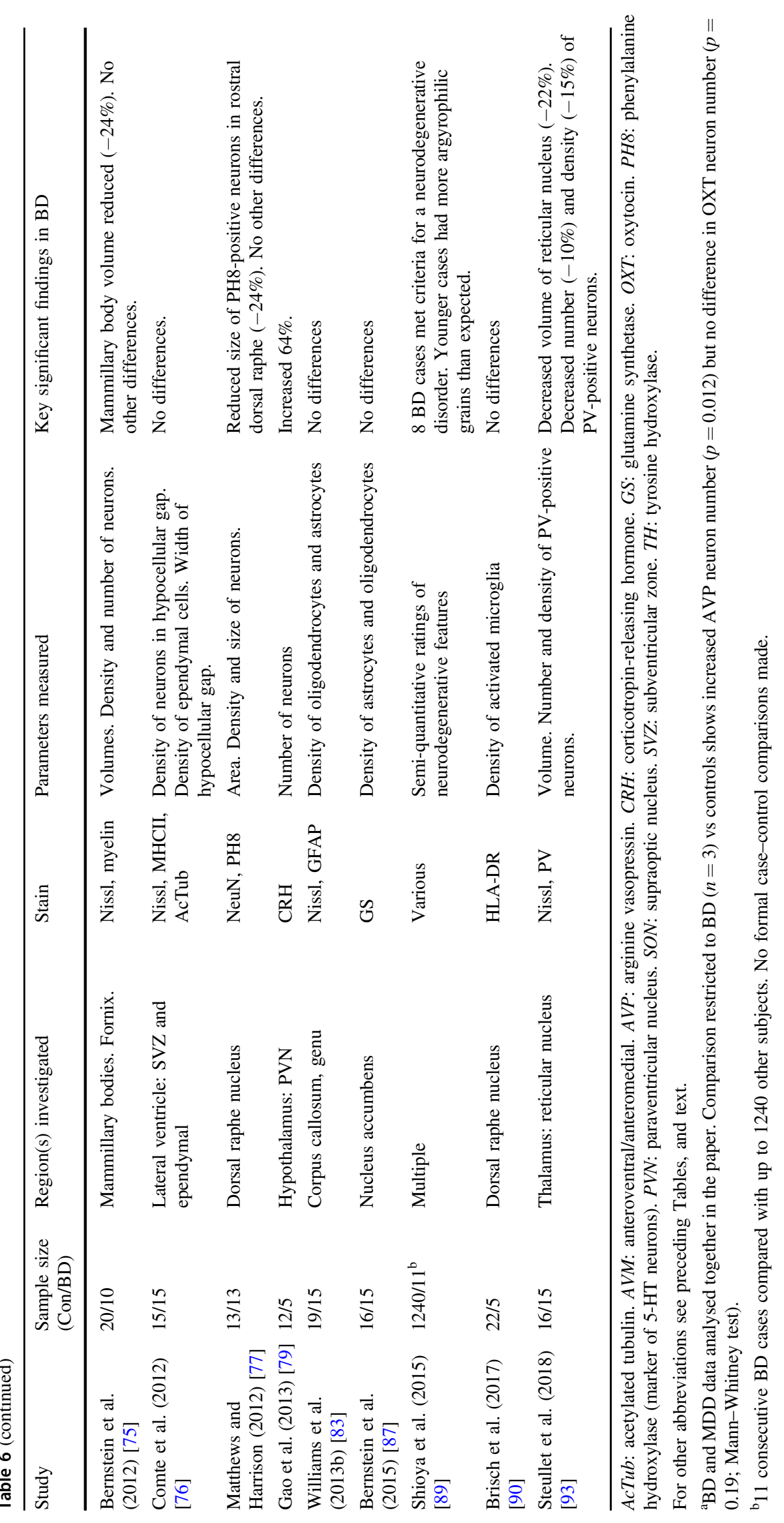




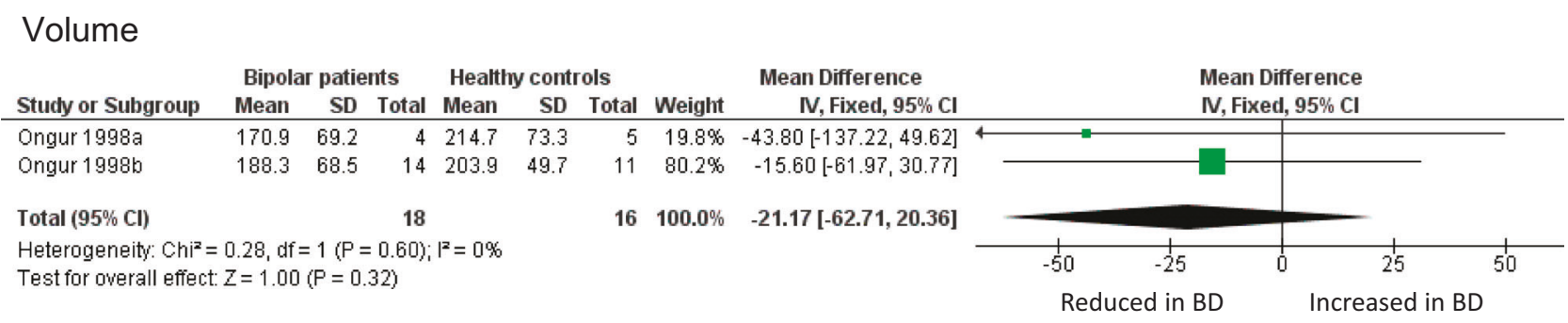

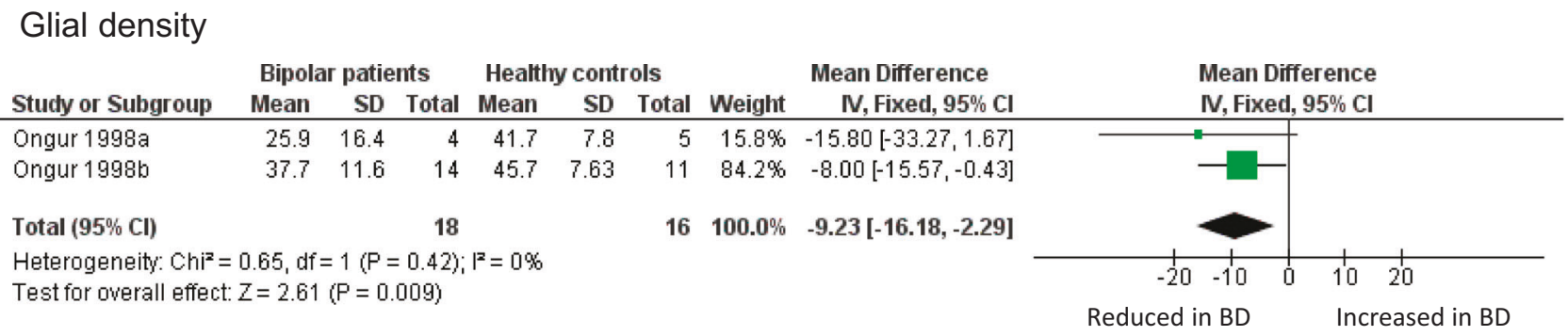

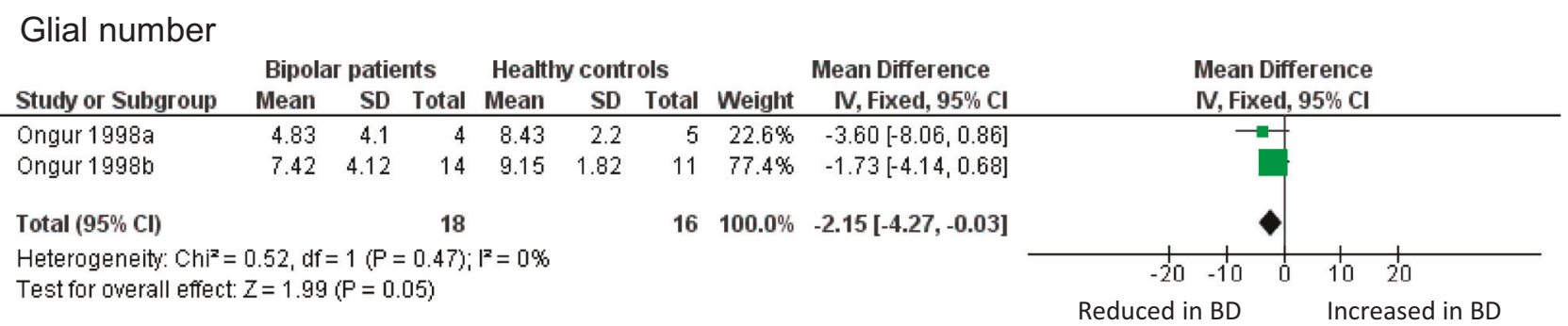

Fig. 1 Meta-analysis of volume, glial density, and glial number in subgenual ACC. Data are taken from the two cohorts included in Öngür et al. [8]. 'Ongur 1998a' refers to their pilot study; 'Ongur 1998 ' refers to the main study, which used brains from the Stanley

most such cells are located) of BA9, with no change in overall neuronal density. The first dedicated, three-dimensional counting study of PFC was by Rajkowska et al. [24], again in BA9. Neuronal density was reduced in layer III, and pyramidal neuron density reduced in layers III and V. Glial density was decreased in layer III, with glial size increases. These authors noted the similarity of the glial findings to those of Öngür et al. [8], and their own findings in major depressive disorder in BA9, and contrasted them with the gliosis which would have been expected were BD a neurodegenerative disorder. Cotter et al. [36], using a twodimensional counting method, did not replicate the findings of Rajkowska et al. [24], with no differences in neuronal density and only a trend reduction in glial density, limited to layer VI; Cotter et al. [36] did find a significant reduction in neuronal size in layers $\mathrm{V}$ and VI. Using the same tissue, Uranova et al. (2004) counted putative oligodendrocytes, and reported that density of these glial cells was decreased in layer VI [44]; the same group later described a reduction of perineuronal oligodendrocytes in layer III [58]. In the only study of its kind in $\mathrm{BD}$, Golgi staining was used to quantify
Foundation. Results are presented as mean differences. Glial density $\left(\right.$ cells $\left./ \mathrm{mm}^{3} \times 10^{3}\right)$ is reduced, with a borderline reduction in glial number $\left(\times 10^{6}\right)$, but no difference in sgACC volume $\left(\mathrm{mm}^{3}\right)$

dendritic parameters of deep layer III pyramidal neurons, and a reduction in dendritic spine number and density, and dendritic length, were identified [85].

Two studies have counted sub-populations of DLPFC interneurons defined by immunoreactivity for the calcium binding proteins calbindin (CB), calretinin (CR) or PV [32, 62]. Beasley et al. [32] found a reduced density of CBimmunoreactive neurons in layers II and III, with no significant differences in CR- or PV-positive neuron. When these data were meta-analysed together with findings from a much smaller study [62], there was a reduction in BD of CBpositive neurons, significant in layers II and III, and overall if all five layers are considered together (Fig. 3). Meta-analysis of these papers also showed a reduction of PV-positive neurons across all layers, but with no significant difference in any one layer (Supplementary Figure 3); CR-positive neurons were unaffected (Supplementary Figure 4). We also metaanalysed studies of DLPFC grey matter thickness (Supplementary Figure 5) and the density of oligodendrocytes in DLPFC white matter (Supplementary Figure 6): neither showed alterations in BD. 


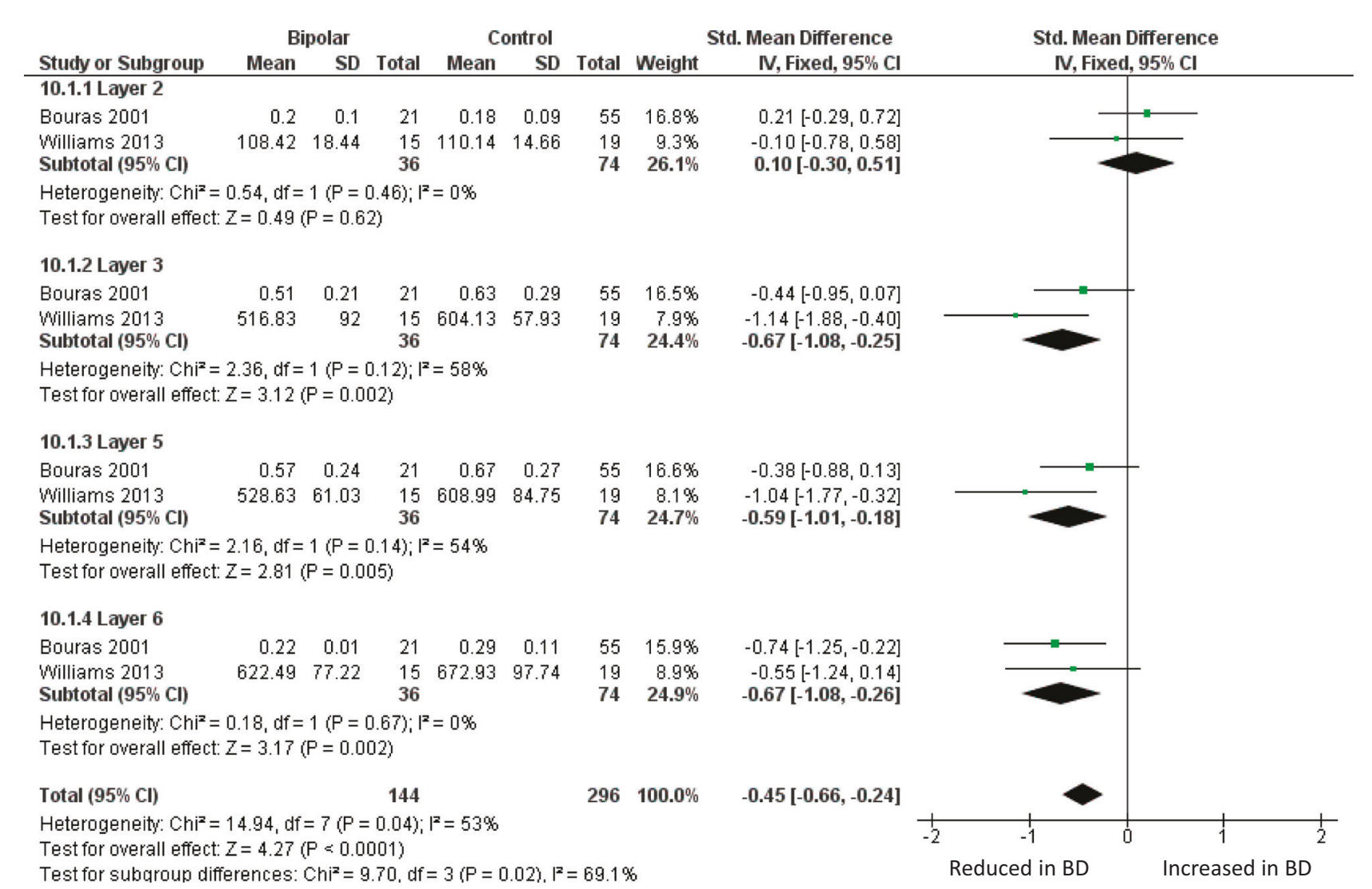

Fig. 2 Meta-analysis of layer thickness in subgenual ACC. Metaanalysis of Bouras et al. [26] and Williams et al. [82] reveals decreased thickness in BD of sgACC layer III (SMD $-0.67, p=0.002)$, layer 5 $(\mathrm{SMD}-0.59, p=0.005)$ and layer VI (SMD $-0.61, p=0.004)$.

In summary, a range of alterations in neuronal and glial morphometry have been reported in DLPFC in BD, but apart from a decrease in density of CB-positive neurons, no specific finding has been replicated.

\section{Amygdala}

The central role of the amygdala in arousal and affect [102, 103], its strong connections with the prefrontal cortex [5], and imaging data in BD [1,5], has made it a structure of neuropathological interest in the disorder [5, 12, 102, 103]. Table 4 summarises the eight studies to date; three considered the amygdala as a single structure, whilst the others focused on one or more amygdaloid nuclei or groupings thereof [104].

The first study, by Bowley et al. in 2002 [34], was conducted to determine whether the amygdala shared the glial reductions seen in ACC and DLPFC. The result was negative, as were subsequent counts of glial subpopulations [43, 54, 65, 70]. Berretta et al. [53] reported a decreased volume of the lateral nucleus, which was confirmed by Pantazopoulos et al. [92] in an expanded
Thickness is also decreased across all four layers considered together (SMD $-0.45, p<0.0001$ ). The data in ref. 82 were originally analysed separately for men and women; they are combined here as described in the text

sample, and who also described a decreased volume of the cortical nucleus. Accompanying the decreased size of the lateral nucleus, reduced neuronal size [54], and a lower neuronal number and density [53] was found. The neuronal reduction in the lateral nucleus is in part due to a loss of somatostatin (SS)-positive neurons [92], whereas in the cortical nucleus, neuropeptide Yimmunoreactive neurons were decreased [92]. The number and density of PV-immunoreactive neurons were not changed in either nucleus [70]. We were able to meta-analyse the two independent studies which measured neuronal density in lateral, basal and accessory basal nuclei $[53,54]$. This revealed significant reductions in all three nuclei in BD (Fig. 4). However, this conclusion is weakened by the fact that Altshuler et al. [65], studying the same material as ref. 53 but with a different delineation of the 'basolateral' amygdala, found no diagnostic effect.

In summary, studies of the amygdala are consistent in showing no alterations in glia in $\mathrm{BD}$, with moderate evidence for reduced density of neurons in lateral, basal and accessory basal nuclei. 


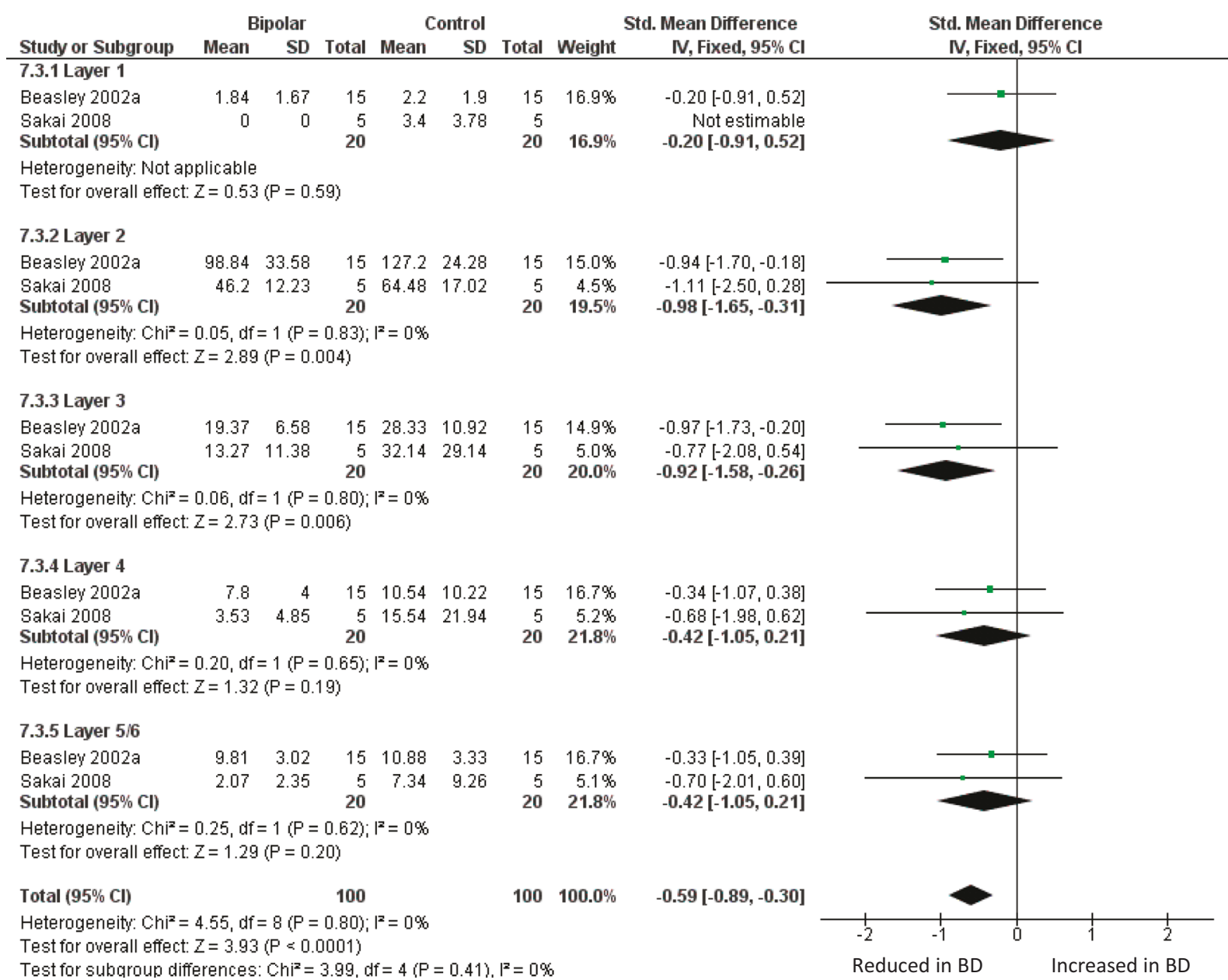

Fig. 3 Meta-analysis of calbindin-immunoreactive neuron density in DLPFC. Meta-analysis of Beasley et al. [32] and Sakai et al. [62]. We used the data for the 'medium' size class of neuron reported in ref. 62. Density of CB-positive neurons is reduced in BD in layer II (SMD

\section{Hippocampus}

Neuropathological studies of the hippocampus (including the subicular complex) in BD are summarised in Table 5.

Like PFC, the hippocampus was studied in BD in part because it had been a major focus in schizophrenia [105, 106]. Indeed, the first such study in BD, by Benes et al. [9], primarily reported schizophrenia data but also included four BD subjects, and found a reduction of neuronal density (in both disorders), selective to CA2 subfield, and affecting non-pyramidal neurons (i.e. interneurons) but not pyramidal neurons. Non-pyramidal neurons in BD were also slightly smaller. Zhang and Reynolds [39] found a markedly reduced density of PV-positive interneurons in all subfields, and a reduced size of these neurons. The next substantive report was in 2011, when Konradi and colleagues carried out a larger, stereological study to measure hippocampal volume and the number and size of neurons, including

$-0.98, p=0.004)$ and layer III (SMD $-0.92, p=0.006$ ), and with an overall significant reduction if all 5 layers are considered together (SMD $-0.59 p<0.0001$ )

interneurons labelled by PV or SS [73]. They found a selective reduction in the volume, and the somal volume, of the non-pyramidal sector of $\mathrm{CA} 2 / 3$, The numbers of both neuropeptide-delineated interneurons were reduced in $\mathrm{BD}$, across all CA fields; pyramidal neurons were unaffected. In a related study, Wang et al. [74] reported PV and SS neuron reductions in the parasubiculum. In a stereological study of the posterior hippocampus, Malchow et al. [88] found no differences in hippocampal subfield volumes in BD (including CA2/3), and an increased number and density of neurons in CA1 and in subiculum; they did not distinguish pyramidal from non-pyramidal neurons. In CA1, oligodendrocyte number was also increased. Meta-analysing the two studies of hippocampal neuron number [73, 88] revealed no differences in any subfield in BD (Supplementary Figure 7; see also Supplementary Table 5).

In summary, there is consistent albeit inconclusive evidence in the hippocampus for reductions of non-pyramidal 


\section{Lateral nucleus}

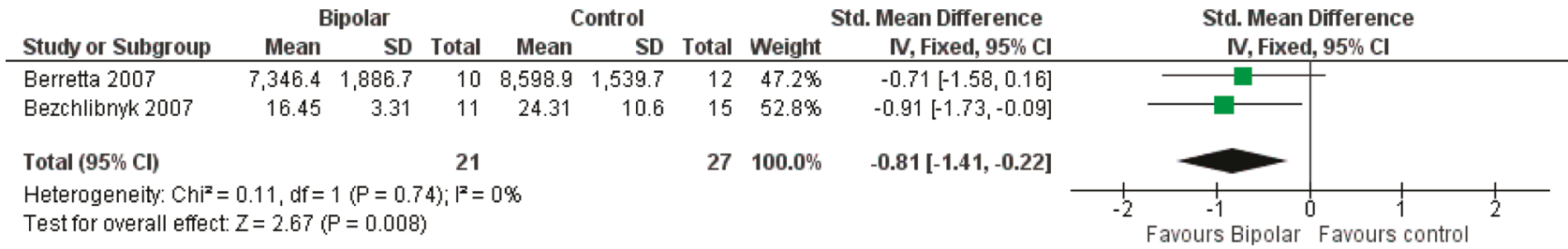

\section{Basal nucleus}

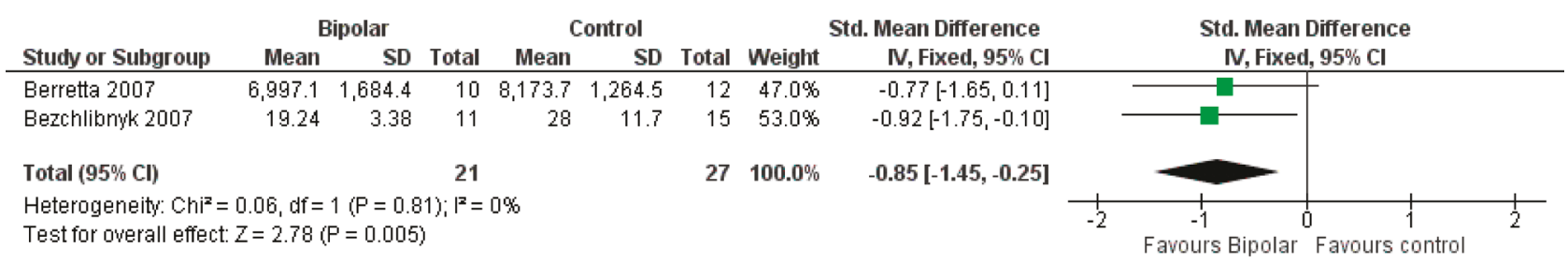

\section{Accessory basal nucleus}

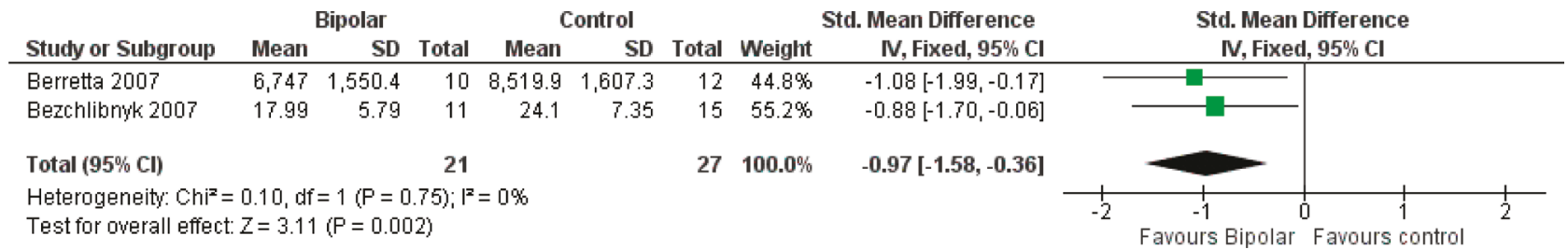

Fig. 4 Meta-analysis of neuronal density in lateral, basal and accessory basal nuclei of the amygdala. Meta-analysis of Berretta et al. [53] and Bezchlibnyk et al. [54]. For the accessory basal nucleus, we combined data from parvocellular and magnocellular subnuclei reported in [54]. Neuronal density is reduced in BD in the lateral nucleus (SMD -0.81 ,

neurons, especially of PV-positive neurons, although differences in methodology and subfields measured precluded meta-analysis. Evidence for involvement of other cell types, or for an altered hippocampal volume, is not compelling.

\section{Other brain regions}

Seven neuropathological studies have examined the entorhinal cortex in BD (Supplementary Table 3). The only replicated positive finding is that the density of PVimmunoreactive neurons is reduced [57, 74]. An unchanged density of GFAP-positive astrocytes has been reported in two studies $[28,70]$, complementing a lack of alteration in overall glial density [34].

Neuropathological investigations of other neocortical regions, sometimes included to determine the anatomical selectivity of changes found in ACC or DLPFC, are essentially negative, as summarised in Supplementary Table 4. This includes a lack of alterations in the density of neurons or glia; the only exception is Brauch et al. (2007) who reported a modest increase in neuronal density in an unspecified region of temporal cortex [51]. $p=0.008$ ), basal nucleus (SMD $-0.85, p=0.005$ ) and accessory basal nucleus (SMD $-0.97, p=0.002$ ). SMDs should be interpreted taking into account the fact that ref. 53 used 3D counting (neurons per unit volume) whereas ref. 54 used 2D counting (neurons per unit area)

In addition to the amygdala, several other subcortical nuclei and regions have been investigated in BD (Table 6). Various differences have been reported, particularly in the hypothalamus [18, 47, 49, 79], but no specific finding has been replicated.

\section{Discussion}

The existence and nature of the neuropathology of psychiatric disorders has been debated for well over a century. Contemporary studies began in earnest in the 1980s, with a focus on schizophrenia, with findings in that disorder informing and encouraging equivalent investigations of other psychiatric disorders, including BD. The latter literature now extends to over 100 empirical studies, of which 81 met our criteria for inclusion in this systematic review. Our findings can be summarised as follows. First, although this is a significant body of work, most studies have relied on a limited number of brain collections, and have used relatively small sample sizes (Table 1) and are thus vulnerable to both type I and type II errors. Second, surprisingly few studies have attempted to replicate closely a previous one, 
precluding substantial meta-analyses; such that the latter were all limited to analysis of two studies each, comprising 16-36 BD cases and 16-74 controls (summarised in Supplementary Table 5). Hence, no neuropathological findings in $\mathrm{BD}$ can be considered to have been unequivocally established. Nevertheless, several findings are significant after meta-analysis of the available data, and merit brief discussion. We also consider the evidence against the presence of gliosis.

\section{Key positive findings}

The sgACC remains of interest, with the findings of glial deficits (Fig. 1) and a thinning of grey matter (Fig. 2) being significant after meta-analysis. Indeed, the latter finding is probably the most robust positive result, given that it is based on two independent studies [26, 82], both using relatively large samples (and comprising the largest combined sample), coupled with a third study showing a similar albeit non-significant trend [78], and the absence of any contradictory reports. The results mean that further neuropathological investigations of the sgACC are warranted, especially given the continuing focus on this region for the pathophysiology and therapeutics of mood disorder [107, 108]. Whether a similar pathology is seen in other parts of the ACC is unclear, since whilst there is some evidence for a thinner layer V (Supplementary Figure 2), glial and neuronal density data are inconsistent, as discussed earlier.

The finding of a reduced density of CB-positive neurons in some layers of DLPFC is significant by meta-analysis (Fig. 3), albeit based on a modest sample size. Caution is also needed when interpreting the summary statistic which arises from considering the cortical layers together, such as the finding of reduced PV-positive neuron density (Supplementary Figure 6), especially given the lack of significant reduction of PV neurons in any one layer. On the other hand, these preliminary indications that interneurons may be affected in BD are supported by findings of a decreased density or number of interneurons, defined by a range of markers, in several brain regions $[22,23,39,57$, $74,92,93]$. No firm conclusions can be drawn regarding these disparate observations, but they do merit further investigation, and complement the well-established involvement of some interneuron populations in schizophrenia [109-112].

Reduced neuronal density has been identified in three nuclei of the amygdala (lateral, basal and accessory basal), arising from two reasonably sized samples by independent investigators using different methodologies ([53, 54]; Fig. 4). The findings support an involvement of the amygdala in the key circuits of BD [5, 12]. Data in other nuclei are insufficient to determine whether the findings reflect a broader distribution of amygdala changes, although the unaltered neuronal density seen in the amygdala as a whole [34] suggests that connections and functions of the laterobasal group of the amygdala may be particularly involved in BD [113-116]. However, as noted earlier, Altshuler et al. [65], using the same brains as Bezchilbnyk et al. [54], found no difference in neuronal density in $\mathrm{BD}$ in the basolateral nucleus. They do not define this structure, but the term conventionally refers to the lateral subdivision of the basal nucleus [104], and hence would have been subsumed within the latter region as measured in refs. 53 and 54 .

\section{Absence of gliosis}

Set against these positive findings, all of which remain to be confirmed beyond doubt, it is worth noting perhaps the clearest conclusion from this systematic review. That is, gliosis (an increase in the density, number or size of glia, especially astrocytes) is not a feature of BD. As summarised in Supplementary Table 6a, no increase in overall glial density has been reported in any of the 19 studies which have measured this parameter (and 4 of them reported reductions). Similarly, of the 12 studies which counted astrocytes (either as identified on Nissl stains, or using immunostaining), 10 reported no differences in BD, and 2 found a reduction (Supplementary Table 6b). Data for oligodendrocytes and microglia are fewer, but again show no consistent pattern of alteration (Supplementary Table $6 \mathrm{c}$ and 6d). Since astrocytic gliosis is usually considered to be indicative of a neurodegenerative process [117, 118], this negative profile of results suggests strongly that $\mathrm{BD}$ is not a disorder of that kind. Similarly, the unchanged density of microglia provides no support for the presence of an underlying neuroinflammatory process. When drawing these conclusions, it should be noted that psychiatric brain banks usually exclude subjects if formal neuropathological examination revealed specific abnormalities, because they are viewed as coincidental and confounding findings. For example, the Stanley Foundation brain collection, used in almost half the studies included here, screened brains 'to rule out Alzheimer's disease and other cerebral pathology' [10]. Nevertheless, as noted by others, the cumulative evidence is strong that $\mathrm{BD}$, like other major psychiatric disorders, is not neurodegenerative in nature $[7,11,24,105$, $117,119]$. By default, these disorders are often viewed as being neurodevelopmental in origin, although the positive evidence in favour of that conclusion comes primarily from epidemiology and functional genomics rather than from neuropathology [120-124].

\section{Interpreting the neuropathological findings}

MRI studies show reductions in grey matter thickness in several cortical regions in $\mathrm{BD}$, including ACC $[2,125]$. As 
noted, there is also good neuropathological evidence for a thinning of $\operatorname{sgACC}$ (Fig. 2). However, in all other cortical areas examined, post mortem studies show minimal or no difference in grey matter thickness in BD [24-26, 32, 40, $42,48,66]$, in contrast to the anatomically widespread MRI findings. There is also a divergence between the robust MRI evidence for decreased volumes of the hippocampus [1] and most of its constituent subfields [126], and the neuropathological studies which are divided, with two reporting reduced hippocampal size $[47,73]$ and two which do not $[9$, 88]. When reconciling observations from the two modalities, it should be borne in mind that the imaging data are based on findings from over 1700 BD patients and 2500 controls, and the differences between BD and controls for each parameter are only $1-2 \%[1,2]$. Hence the neuropathological studies (which are about two orders of magnitude smaller; Table 1) are grossly underpowered to detect such differences. It is also possible that the group differences seen on neuroimaging are not exclusively reflective of brain structure, but have other potential interpretations and confounders [127], including the effects of lithium [128, 129].

The diagnostic status of BD and its relationships with schizophrenia and major depressive disorder continue to be under active debate clinically and genetically. This issue also has a neuropathological dimension. As noted earlier, the majority of BD studies also include one or both of these other disorders. Although it is beyond the scope of this systematic review to perform a comparative analysis, it is apparent that there is no consistent pattern of similarities or differences between these disorders (with the exception of the absence of gliosis, which is a common observation). Thus, some reported positive findings are specific to BD (e.g. [54]), some are common to all three disorders (e.g. [40, 44]), some affect BD and schizophrenia (e.g [26]), and others are shared by BD and major depressive disorder (e.g. [48]). Equally, other parameters are altered in schizophrenia and/or major depressive disorder but not in BD (e.g. [27, 63]). Overall, therefore, the neuropathological data are in line with the view, supported strongly by genomic findings $[130,131]$, that BD, schizophrenia and major depressive disorder are not distinct disorders, but have many features in common as well as some which distinguish them. It is also possible that some of the heterogeneity in the neuropathological data reflects the fact that there are morphological correlates of the genetic predisposition to BD as well as to the syndrome itself $[132,133]$.

This latter point relates to perhaps the most fundamental interpretational issue. The nature of the findings - modest reductions in volume, and in the content of neurons or glia, in certain brain regions - cannot be assumed to be pathological in the sense that lesions such as neurofibrillary tangles or infarcts are. They might instead reflect pre- existing (and partly genetically-mediated) differences in brain structure and connectivity which render the person vulnerable to $\mathrm{BD}$. Or, the extant morphometric findings could be secondary to the illness in some way, e.g. cell loss or atrophy secondary to chronic stress, reduced neurotrophic factor support, etc. These issues are impossible to disentangle using post mortem studies alone, and require triangulation of neuropathological data with other findings, such as neuroimaging and relevant model systems.

\section{Limitations}

In addition to the diagnostic issues and power considerations mentioned earlier, the literature has several other limitations to consider. The first concerns clinical phenotyping. For most studies, there is sparse information available, for example regarding the age of onset and main features of $\mathrm{BD}$; the mood state at death; the presence of comorbid disorders, etc. In any event, the small sample sizes preclude any meaningful attempts at subdividing BD or correlating clinical or demographic variables with neuropathological parameters. Even the clinical diagnosis of BD itself is not straightforward when made on retrospective review of case notes or interview with relatives: DeepSoboslay et al. [134] found that only about half of cases referred to their brain bank as BD met (DSM-IV) diagnostic criteria, with the remainder having inadequate documentation and/or substantial comorbid substance abuse. Other variables such as family history, brain hemisphere and sex could also influence neuropathological findings (e.g., refs. $[8,82,88])$, but have not been reported consistently or in sufficient detail to allow us to examine these factors. There may also be confounding by medications used in BD, since mood stabilisers, antipsychotics and antidepressants can all impact on neuronal and glial indices; such effects may either contribute to, or mitigate, the reported alterations [135-139]. Finally, the neuropathological studies of BD have been of variable methodological quality. For example, only the minority unequivocally meet stereological criteria; the remainder are subject to the limitations and potential biases of studies which do not adhere to these principles [140, 141]. Also, studies differ in the statistical approaches taken, such as whether significance values were adjusted for multiple comparisons (e.g. for the number of cortical layers examined).

\section{Conclusions}

There remain no neuropathological correlates of BD of sufficient robustness, magnitude, and specificity, to be of clinical or diagnostic value. Clearly, this does not rule out the possibility, but it is unlikely that a neuropathology - in 
the conventional sense of the term - exists and which has avoided discovery. Nevertheless, the key findings of this systematic review do merit further study to either confirm or refute them. This would require research of a much larger scale and scope than has occurred to date, to ensure the results are conclusive, and to allow assessment of potential clinico-pathological correlates and subgroupings. This would be a challenging undertaking, but transcriptomic and other molecular studies of psychiatric disorders, including $\mathrm{BD}$, now routinely include many hundreds of brains (e.g. refs. [123, 142, 143]). Neuropathological research should have similar aspirations.

Acknowledgements We thank Andrea Cipriani for expert advice and assistance. LC is funded by the Wellcome Trust Oxford Clinical Doctoral Fellowship Programme. PJH's research is supported by the Wellcome Trust, Medical Research Council, and Oxford Health National Institute for Health Research (NIHR) Biomedical Research Centre. The views expressed are those of the authors and not necessarily those of the National Health Service, NIHR or the Department of Health.

\section{Compliance with ethical standards}

Conflict of interest The authors declare that they have no conflict of interest.

Open Access This article is licensed under a Creative Commons Attribution 4.0 International License, which permits use, sharing, adaptation, distribution and reproduction in any medium or format, as long as you give appropriate credit to the original author(s) and the source, provide a link to the Creative Commons license, and indicate if changes were made. The images or other third party material in this article are included in the article's Creative Commons license, unless indicated otherwise in a credit line to the material. If material is not included in the article's Creative Commons license and your intended use is not permitted by statutory regulation or exceeds the permitted use, you will need to obtain permission directly from the copyright holder. To view a copy of this license, visit http://creativecommons. org/licenses/by/4.0/.

\section{References}

1. Hibar DP, Westlye LT, van Erp TG, Rasmussen J, Leonardo CD, Faskowitz J, et al. Subcortical volumetric abnormalities in bipolar disorder. Mol Psychiatry. 2016;12:1710-1716.

2. Hibar DP, Westlye LT, Doan NT, Jahanshad N, Cheung JW, Ching CRK, et al. Cortical abnormalities in bipolar disorder: an MRI analysis of 6503 individuals from the ENIGMA Bipolar Disorder Working Group. Mol Psychiatry. 2018;4:932-942.

3. Wise T, Radua J, Via E, Cardoner N, Abe O, Adams TM, et al. Common and distinct patterns of grey-matter volume alteration in major depression and bipolar disorder: evidence from voxelbased meta-analysis. Mol Psychiatry. 2017;22:1455-1463.

4. Pezzoli S, Emsell L, Yip SW, Dima D, Giannakopoulos P, Zarei $\mathrm{M}$, et al. Meta-analysis of regional white matter volume in bipolar disorder with replication in an independent sample using coordinates, T-maps, and individual MRI data. Neurosci Biobehav Rev. 2018;84:162-170.
5. Phillips ML, Swartz HA. A critical appraisal of neuroimaging studies of bipolar disorder: toward a new conceptualization of underlying neural circuitry and a road map for future research. Am J Psychiatry. 2014;8:829-843.

6. Wise T, Radua J, Nortje G, Cleare AJ, Young AH, Arnone D. Voxel-based meta-analytical evidence of structural disconnectivity in major depression and bipolar disorder. Biol Psychiatry. 2016;4:293-302.

7. Vawter MP, Freed WJ, Kleinman JE. Neuropathology of bipolar disorder. Biol Psychiatry. 2000;6:486-504.

8. Öngür D, Drevets WC, Price JL. Glial reduction in the subgenual prefrontal cortex in mood disorders. Proc Natl Acad Sci USA. 1998;95:13290-13295.

9. Benes FM, Kwok EW, Vincent SL, Todtenkopf MS. A reduction of nonpyramidal cells in sector CA2 of schizophrenics and manic depressives. Biol Psychiatry. 1998;44:88-97.

10. Torrey EF, Webster M, Knable M, Johnston N, Yolken RH. The Stanley Foundation brain collection and neuropathology consortium. Schizophr Res. 2000;2:151-155.

11. Harrison PJ. The neuropathology of primary mood disorder. Brain. 2002;125:1428-1449.

12. Price JL, Drevets WC. Neurocircuitry of mood disorders. Neuropsychopharmacology. 2010;35:192-216.

13. Savitz JB, Price JL, Drevets WC. Neuropathological and neurormorphometric abnormalities in bipolar disorder: view from the prefrontal cortical network. Neurosci Biobehav Rev. 2014;42:132-147.

14. Higgins JPT, Green S (eds). Cochrane Handbook for Systematic Reviews of Interventions Version 5.1.0 [updated March 2011]. The Cochrane Collaboration. 2011. Available from www.cochra ne-handbook.org.

15. Elvidge AR, Reed GE. Biopsy studies of cerebral pathologic changes in schizophrenia and manic-depressive psychosis. Arch Neurol Psychiatry. 1938;40:227-268.

16. Nasrallah HA, McCalley-Whitters M, Bigelow LB, Rauscher FP. A histological study of the corpus callosum in chronic schizophrenia. Psychiatry Res. 1983;8:251-260.

17. Beckmann H, Jakob H. Prenatal disturbances of nerve cell migration in the entorhinal region: a common vulnerability factor in the functional psychoses? J Neural Transm Gen Sect. 1991;84:155-164.

18. Purba JS, Hoogendijk WJG, Hofman MA, Swaab DF. Increased numbers of vasopressin- and oxytocin-expressing neurons in the paraventricular nucleus of the hypothalamus in depression. Arch Gen Psychiatry. 1996;53:137-143.

19. Baumann B, Danos P, Krell D, Diekmann S, Wurthmann C, Bielau $\mathrm{H}$, et al. Unipolar-bipolar dichotomy of mood disorders is supported by noradrenergic brainstem system morpholoy. J Affect Dis. 1999a;54:217-224.

20. Baumann B, Danos P, Diekmann S, Krell D, Bielau H, Geretsegger $\mathrm{C}$, et al. Tyrosine hydroxylase immunoreactivity in the locus ceruleus is reduced in depressed non-suicidal patients but normal in depressed suicide patients. Eur Arch Psychiatry Clin Neurosci. 1999b;249:212-219.

21. Helmkamp CE, Bigelow LB, Paltan-Ortiz JD, Torrey EF, Kleinman JE, Herman MM. Evaluation of vermal Purkinje cell placement in mental illness. Biol Psychiatry. 1999;45:1370-1375.

22. Fatemi SH, Earle JA, McMenomy T. Reduction in Reelin immunoreactivity in hippocampus of subjects with schizophrenia, bipolar disorder and major depression. Mol Psychiatry. 2000;6:654-663.

23. Guidotti A, Auta J, Davis JM, DiGiorgi Gerevini V, Dwivedi Y, Grayson DR, et al. Decrease in reelin and glutamic aciddecarboylase67 (GAD67) expression in schizophrenia and 
bipolar disorder. A postmortem brain study. Arch Gen Psychiatry. 2000;57:1061-1069.

24. Rajkowska G, Halaris A, Selemon LD. Reductions in neuronal and glial density characterize the dorsolateral prefrontal cortex in bipolar disorder. Biol Psychiatry. 2001;49:741-752.

25. Benes FM, Vincent SL, Todtenkopf MS. The density of pyramidal and nonpyramidal neurons in anterior cingulate cortex of schizophrenc and bipolar subjects. Biol Psychiatry. 2001;50:395-406.

26. Bouras C, Kövari E, Hof PR, Riederer BM, Giannokopoulos P. Anterior cingulate pathology in schizophrenia and bipolar disorder. Acta Neuropathol. 2001;102:373-379.

27. Cotter D, Mackay D, Landau S, Kerwin R, Everall I. Reduced glial cell density and neuronal size in the anterior cingulate cortex in major depressive disorder. Arch Gen Psychiatry. 2001;58:545-553.

28. Damadzic R, Bigelow LB, Krimer LS, Goldenson DA, Saunders $\mathrm{RC}$, Kleinman JE, et al. A quantitative immunohistochemical study of astrocytes in the entorhinal cortex in schizophrenia, bipolar disorder and major depression: Absence of significant astrocytosis. Brain Res Bull. 2001;55:611-618.

29. Uranova N, Orlovskaya D, Vikhereva O, Zimina I, Kolomeets N, Vostrikov V, et al. Electron microscopy of oligodendroglia in severe mental illness. Brain Res Bull. 2001;55:597-610.

30. Webster MJ, Knable MB, Johnston-Wilson N, Nagata K, Inagaki $\mathrm{M}$, Yolken RH. Immuno-histochemical localization of phosphorylated glial fibrillary acidic protein in the prefrontal cortex and hippocampus from patients with schizophrenia, bipolar disorder, and depression. Brain Behav Immun. 2001;15:388-401.

31. Baumann B, Bielau H, Krell D, Agelnik MW, Diekmann S, Wurthmann C, et al. Circumscribed numerical deficit of dorsal raphe neurons in mood disorders. Psychol Med. 2002;32:93-103.

32. Beasley CL, Zhang ZJ, Patten I, Reynolds GP. Selective deficits in prefrontal cortical GABAergic neurons in schizophrenia defined by the presence of calcium-binding proteins. Biol Psychiatry. 2002a;52:708-715.

33. Beasley CL, Cotter DR, Everall IP. Density and distribution of white matter neurons in schizophrenia, bipolar disorder and major depressive disorder: no evidence for abnormalities of neuronal migration. Mol Psychiatry. 2002b;7:564-570.

34. Bowley MP, Drevets WC, Öngür D, Price JL. Low glial numbers in the amygdala in major depressive disorder. Biol Psychiatry. 2002;52:404-412.

35. Cotter D, Landau S, Beasley C, Stevenson R, Chana G, MacMillan L, et al. The density and spatial distribution of GABAergic neurons, labelled using calcium binding proteins, in the anterior cingulate cortex in major depressive disorder, bipolar disorder, and schizophrenia. Biol Psychiatry. 2002a;51:377-386.

36. Cotter D, Mackay D, Chana G, Beasley C, Landau S, Everall IP. Reduced neuronal size and glial cell density in area 9 of the dorsolateral prefrontal cortex in subjects with major depressive disorder. Cereb Cortex. 2002b;12:386-394.

37. Damadzic R, Shuangshoti S, Giblen G, Herman MM. Neuritic pathology is lacking in the entorhinal cortex, subiculum and hippocampus in middle-aged adults with schizophrenia, bipolar disorder or unipolar depression. Acta Neuropathol. 2002;103:488-494.

38. Gilmore JH, Bouldin T. Analysis of ependymal abnormalities in subjects with schizophrenia, bipolar disorder, and depression. Schizophr Res. 2002;57:267-271.

39. Zhang ZJ, Reynolds GP. A selective decrease in the relative density of parvalbumin-immunoreactive neurons in the hippocampus in schizophrenia. Schizophr Res. 2002;55:1-10.

40. Chana G, Landau S, Beasley C, Everall IP, Cotter D. Twodimensional assessment of cytoarchitecture in the anterior cingulate cortex in major depressive disorder, bipolar disorder, and schizophrenia: evidence for decreased neuronal somal sized and increased neuronal density. Biol Psychiatry. 2003;53:108-1098.

41. Law AJ, Harrison PJ. The distribution and morphology of prefrontal cortex pyramidal neurons identified using antineurofilament antibodies SMI32, N200 and FNP7. Normative data and a comparison in subjects with schizophrenia, bipolar disorder or major depression. J Psychiatr Res. 2003;37:487-499.

42. Cotter D, Mackay D, Frangou S, Hudson L, Landau S. Cell density and cortical thickness in Heschl's gyrus in schizophrenia, major depression and bipolar disorder. $\mathrm{Br} \mathrm{J}$ Psychiatry. 2004;185:258-259.

43. Hamidi M, Drevets WC, Price JL. Glial reduction in amygdala in major depressive disorder is due to oligodendrocytes. Biol Psychiatry. 2004;55:563-569.

44. Uranova N, Vostrikov VM, Orlovskaya DD, Rachmanova VI. Oligodendroglial density in the prefrontal cortex in schizophrenia and mood disorders: a study from the Stanley Neuropathology Consortium. Schizophr Res. 2004;67:269-275.

45. Young KA, Holcomb LA, Yazdani U, Hicks PB, German DC. Elevated neuron number in the limbic thalamus in major depression. Am J Psychiatry. 2004;161:1270-1277.

46. Beasley CL, Chana G, Honavar M, Landau S, Everall IP, Cotter D. Evidence for altered neuronal organisation within the planum temporale in major psychiatric disorders. Schizophr Res. 2005;73:69-78.

47. Bielau H, Trübner K, Krell D, Agelnik MW, Bernstein H-G, Stauch R, et al. Volume deficits of subcortical nuclei in mood disorders. Eur Arch Psychiatry Clin Neurosci. 2005;255:401-412.

48. Cotter D, Hudson L, Landau S. Evidence for orbitofrontal pathology in bipolar disorder and major depression, but not in schizophrenia. Bipolar Disord. 2005;7:358-369.

49. Manaye KF, Lei D-L, Tizabi Y, Davila-Garcia MI, Mouton PR, Kelly PH. Selective neuron loss in the paraventricular nucleus of hypothalamus in patients suffering from major depression and bipolar disorder. J Neuropathol Exp Neurol. 2005;64:224-229.

50. Todtenkopf MS, Vincent SL, Benes FM. A cross-study metaanalysis and three-dimensional comparison of cell counting in the anterior cingulate cortex of schizophrenic and bipolar brain. Schizophr Res. 2005;73:79-89.

51. Brauch RA, El-Masri MA, Parker JC Jr, El-Mallakh RS. Glial cell number and neuron/glial cell ratios in postmortem brains of bipolar individuals. J Affect Disord. 2007;91:87-90.

52. Toro CT, Hallak JEC, Dunham JS, Deakin JFW. Glial fibrillary acidic protein and glutamine synthetase in subregions of prefrontal cortex in schizophrenia and bipolar disorder. Neurosci Lett. 2006;404:276-281.

53. Berretta S, Pantazopoulos H, Lange N. Neuron numbers and volume of the amygdala in subjects diagnosed with bipolar disorder or schizophrenia. Biol Psychiatry. 2007;62:884-893.

54. Bezchlibnyk YB, Sun X, Wang J-F, MacQueen GM, McEwen BS, Young LT. Neuron somal size is decreased in the lateral amygdalar nucleus of subjects with bipolar disorder. J Psychiatry Neurosci. 2007;32:203-210.

55. Bielau H, Steiner J, Mawrin C, Trübner K, Brisch R, Meyer-Lotz $\mathrm{G}$, et al. Dysregulation of GABAergic neurotransmission in mood disorders, a postmortem study. Ann N Y Acad Sci. 2007;1096:157-169.

56. Liu L, Schulz C, Lee S, Reutimann TJ, Fatemi SH. Hippocampal CA1 pyramidal cell size is reduced in bipolar disorder. Cell Mol Neurobiol. 2007;27:351-358.

57. Pantazopoulos H, Lange N, Baldessarini RJ, Berretta S. Parvalbumin neurons in the entorhinal cortex of subjects diagnosed 
with bipolar disorder or schizophrenia. Biol Psychiatry. 2007;61:640-652.

58. Vostrikov VM, Uranova NA, Orlovskaya DD. Deficit of perineuronal oligodendrocytes in schizophrenia and mood disorders. Schizophr Res. 2007;94:273-280.

59. Young KA, Holcomb LA, Bonkale WL, Hicks PB, Yazdani U, German DC. 5HTTPLR polymorphism and enlargement of the pulvinar: unlocking the backdoor to the limbic system. Biol Psychiatry. 2007;61:813-818.

60. Byne W, Tatusov A, Yiannoulos G, Vong GS, Marcus S. Effects of mental illness and aging in two thalamic nuclei. Schizophr Res. 2008;106:172-181.

61. Pennington K, Dicker P, Hudson L, Cotter DR. Evidence for reduced neuronal somal size within the insular cortex in schizophrenia, but not in affective disorders. Schizophr Res. 2008;106:164-171.

62. Sakai T, Oshima A, Nozaki Y, Ida I, Haga C, Akiyama H, et al. Changes in density of calcium-binding-protein-immunoreactive GABAergic neurons in prefrontal cortex in schizophrenia and bipolar disorder. Neuropathology. 2008;28:143-150.

63. Beasley CL, Honavar M, Everall IP, Cotter D. Two-dimensional assessment of cytoarchitecture in the superior temporal cortex white matter in schizophrenia, major depressive disorder and bipolar disorder. Schizophr Res. 2009;115:156-162.

64. Connor CM, Guo Y, Akbarian S. Cingulate white matter neurons in schizophrenia and bipolar disorder. Biol Psychiatry. 2009;66:486-493.

65. Altshuler LL, Abulseoud OA, Foland-Ross L, Bartzokis G, Chang S, Mintz J, et al. Amygdala astrocyte reduction in subjects with major depressive disorder but not bipolar disorder. Bipolar Disord. 2010;12:541-549.

66. Brüne M, Schöbel A, Karu R, Benali A, Fasutmann PM, Juckel $\mathrm{G}$, et al. Von Economo neuron density in the anterior cingulate cortex is reduced in early onset schizophrenia. Acta Neuropathol. 2010;119:771-778.

67. Cataldo AM, McPhie DL, Lange NT, Punzell S, Elmiligy S, Ye $\mathrm{NZ}$, et al. Abnormalities in mitochondrial structure in cells from patients with bipolar disorder. Am J Pathol. 2010;177:575-585.

68. Hercher C, Canetti L, Turecki G, Mechawar N. Anterior cingulate pyramidal neurons display altered dendritic branching in depressed suicides. J Psychiatr Res. 2010;44:286-93.

69. Maloku E, Covelo IR, Hanbauer I, Guidotti A, Kadriu B, Hu Q, et al. Lower number of cerebellar Purkinje neurons in psychosis is associated with reduced reelin expression. Proc Natl Acad Sci USA. 2010;107:4407-4411.

70. Pantazopoulos H, Woo T-UW, Lim MP, Lange N, Berretta S. Extracellular matrix-glial abnormalities in the amygdala and entorhinal cortex of subjects diagnosed with schizophrenia. Arch Gen Psychiatry. 2010;67:155-166.

71. Ranft K, Dobrowolny H, Krell D, Bielau H, Bogerts B, Bernstein H-G. Evidence for structural abnormalities of the human habenular complex in affective disorders but not in schizophrenia. Psychol Med. 2010;40:557-567.

72. Brisch R, Bernstein H-G, Dobrowolny H, Krell D, Stauch R, Trubner K, et al. A morphometric analysis of the septal nuclei in schizophrenia and affective disorders: reduced neuronal density in the lateral septal nucleus in bipolar disorder. Eur Arch Psychiatry Clin Neurosci. 2011;261:47-58

73. Konradi C, Zimmerman EI, Yang K, Lohmann KM, Gresch P, Pantazopoulos $\mathrm{H}$, et al. Hippocampal interneurons in bipolar disorder. Arch Gen Psychiatry. 2011;68:340-350.

74. Wang AY, Lohmann KM, Yang CK, Zimmerman EI, Pantazopoulos $\mathrm{H}$, Herring N, et al. Bipolar disorder type I and schizophrenia are accompanied by decreased density of parvalbuminand somatostatin-positive interneurons in the parahippocampal region. Acta Neuropathol. 2011;122:615-626.
75. Bernstein H-G, Klix M, Dobrowolny H, Brisch R, Steiner J, Bielau $\mathrm{H}$, et al. A postmortem assessment of mammillary body volume, neuronal number and densities, and fornix volume in subjects with mood disorders. Eur Arch Psychiatry Neurosci. 2012;262:637-646.

76. Comte I, Kotagiri P, Szele FG. Regional differences in human ependymal and subventricular zone cytoarchitecture are unchanged in neuropsychiatric disease. Dev Neurosci. 2012;34:299-309.

77. Matthews PR, Harrison PJ. A morphometric, immunohistochemical, and in situ hybridization study of the dorsal raphe nucleus in major depression, bipolar disorder, schizophrenia, and suicide. J Affect Disord. 2012;137:125-134.

78. Sinka L, Kovari E, Santos M, Herrmann FR, Gold G, Hof PR, et al. Microvascular changes in late-life schizophrenia and mood disorders: stereological assessment of capillary diameters in anterior cingulate cortex. Neuropathol Appl Neurobiol. 2012;38:696-709.

79. Gao S-F, Klomp A, Wu J-L, Swaab DF, Bao A-M. Reduced $\mathrm{GAD}_{65 / 67}$ immunoreactivity in the hypothalamic paraventricular nucleus in depresison: a postmortem study. J Affect Disord. 2013;143:422-425.

80. Gos T, Schroeter ML, Lessel W, Bernstein H-G, Dobrowolny H, Schiltz K, et al. S100B-immunopositive astrocytes and oligodendrocytes in the hippocampus are differentially afflicted in unipolar and bipolar depression: a postmortem study. J Psychiatr Res. 2013;47:1694-1699.

81. Mosebach J, Keilhoff G, Gos T, Schiltz K, Schoeneck L, Dobrowolny $\mathrm{H}$, et al. Increased nuclear Olig1-expression in the pregenual anterior cingulate white matter of patients with major depression: a regenerative attempt to compensate oligodendrocyte loss? J Psychiatr Res. 2013;47:1069-1079.

82. Williams MR, Chaudhry R, Perera S, Pearce RKB, Hirsch SR, Ansorge $\mathrm{O}$, et al. Changes in cortical thickness in the frontal lobes in schizophrenia are a result of thinning of pyramidal cell layers. Eur Arch Psychiatry Clin Neurosci. 2013a;263:25-39.

83. Williams MR, Hampton T, Pearce RKB, Hisrch SR, Ansorge O, Thom M, et al. Astrocyte decrease in the subgenual cingulate and callosal genu in schizophrenia. Eur Arch Psychiatry Clin Neurosci. 2013b;263:41-52.

84. Hercher C, Chopra V, Beasley CL. Evidence for morphological alterations in prefrontal white matter glia in schizophrenia and bipolar disorder. J Psychiatry Neurosci. 2014;39: 376-385.

85. Konopaske GT, Lange N, Coyle JT, Benes FM. Prefrontal cortical dendritic spine pathology in schizophrenia and bipolar disorder. JAMA Psychiatry. 2014;71:1323-1331.

86. Williams MR, Pearce RKB, Hirsch SR, Ansorge O, Thom M, Maier M. Fibrillary astrocytes are decreased in the subgenual cingulate in schizophrenia. Eur Arch Psychiatry Clin Neurosci. 2014;264:357-362.

87. Bernstein H-G, Meyer-Lotz G, Dobrowolny H, Bannier J, Steiner J, Walter M, et al. Reduced density of glutamine synthetase immunoreactive astrocytes in different cortical areas in major depression but not in bipolar I disorder. Front Cell Neurosci. 2015;9:273

88. Malchow B, Strocka S, Frank F, Bernstein H-G, Steiner J, Schneider-Axmann T, et al. Stereological investigation of the posterior hippocampus in affective disorders. J Neural Transm. 2015;122:1019-1023.

89. Shioya A, Saito Y, Arima K, Kakuta Y, Yuzuriha T, Tanaka N, et al. Neurodegenerative changes in patients with clinical history of bipolar disorders. Neuropathol. 2015;35:245-253.

90. Brisch R, Steiner J, Mawrin C, Krzyzanowska M, Jankowski Z, Gos T. Microglia in the dorsal raphe nucleus plays a potential 
role in both suicide facilitation and prevention in affective disorders. Eur Arch Psychiatry Clin Neurosci. 2017;267:403-415.

91. Krause M, Theiss C, Brüne M. Ultrastructural alterations of von Economo neurons in the anterior cingulate cortex in schizophrenia. Anat Rec. 2017;300:2017-2024.

92. Pantazopoulos H, Wiseman JT, Markota M, Ehrenfeld L, Berretta S. Decreased numbers of somatostatin-expressing neurons in the amygdala of subjects with bipolar disorder or schizophrenia: relationship to circadian rhythms. Biol Psychiatry. 2017;81:536-547.

93. Steullet P, Cabungcal J-H, Bukhari SA, Ardelt MI, Pantazaopoulos $\mathrm{H}$, Hamati $\mathrm{F}$, et al. The thalamic reticular nucleus in schizophrenia and bipolar disorder: role of parvalbuminexpressing neuron networks and oxidative stress. Mol Psychiatry (AOL 28 November 2017; https://doi.org/10.1038/mp. 2017.230

94. Devinsky O, Morrell MJ, Vogt BA. Contributions of anterior cingulate cortex to behaviour. Brain. 1995;118:279-306.

95. Bush G, Liu P, Posner MI. Cognitive and emotional influences in anterior cingulate cortex. Trends Cogn Sci. 2000;4: $215-222$

96. Gittins R, Harrison PJ. Neuronal density, size and shape in the human anterior cingulate cortex: a comparison of Nissl and NeuN staining. Brain Res Bull. 2004;63:155-60.

97. Drevets WC, Price JL, Simpson JR Jr, Todd RD, Reich T, Vannier M, et al. Subgenual prefrontal cortex abnormalities in mood disorders. Nature . 1997;386:824-7.

98. Weinberger DR. Implications of normal brain development for the pathogenesis of schizophrenia. Arch Gen Psychiatry. 1987;44:660-669.

99. Goldman-Rakic PS, Selemon LD. Functional and anatomical aspects of prefrontal pathology in schizophrenia. Schizophr Bull. 1997;23:437-58.

100. Ferrier IN, Stanton BR, Kelly TP, Scott J. Neuropsychological function in euthymic patients with bipolar disorder. Br J Psychiatry. 1999;175:246-51.

101. Sweeney JA, Kmiec JA, Kupfer DJ. Neuropsychologic impairments in bipolar and unipolar mood disorders on the CANTAB neurocognitive battery. Biol Psychiatry. 2000;48:674-84.

102. Phelps EA, LeDoux JE. Contributions of the amygdala to emotion processing: from animal models to human behavior. Neuron. 2005;48:175-87.

103. Pessoa L, Adolphs R. Emotion processing and the amygdala: from a 'low road' to 'many roads' of evaluating biological significance. Nat Rev Neurosci. 2010;11:773-83.

104. Amunts K, Kedo O, Kindler M, Pieperhoff P, Mohlberg H, Shah $\mathrm{NJ}$, et al. Cytoarchitectonic mapping of the human amygdala, hippocampal region and entorhinal cortex: intersubject variability and probability maps. Anat Embryol (Berl). 2005;210:343-52.

105. Harrison PJ. The neuropathology of schizophrenia. A critical review of the data and their interpretation. Brain. 1999;122:593-624.

106. Harrison PJ. The hippocampus in schizophrenia: a review of the neuropathological evidence and its pathophysiological implications. Psychopharmacology (Berl). 2004;174: 151-62.

107. Fox MD, Buckner RL, White MP, Greicius MD, Pascual-Leone A. Efficacy of transcranial magnetic stimulation targets for depression is related to intrinsic functional connectivity with the subgenual cingulate. Biol Psychiatry. 2011;72: 595-603.

108. Riva-Posse P, Choi KS, Holtzheimer PE, McIntyre CC, Gross RE, Chaturvedi A, et al. Defining critical white matter pathways mediating successful subcallosal cingulate deep brain stimulation for treatment-resistant depression. Biol Psychiatry. 2014;76:963-969.
109. Benes FM, Berretta S. GABAergic interneurons: implications for understanding schizophrenia and bipolar disorder. Neuropsychopharmacol. 2001;25:1-27.

110. Harrison PJ, Lewis DA, Kleinman JE. Neuropathology of schizophrenia. In: Weinberger DR, Harrison PJ, editors. Schizophrenia, 3rd edition. Oxford: Wiley-Blackwell, pp 372-392.

111. Gonzalez-Burgos G, Cho Y, Lewis DA. Alterations in cortical network oscillations and parvalbumin neurons in schizophrenia. Biol Psychiatry. 2015;77:1031-1040.

112. Schmidt MT, Mirnics K. Neurodevelopment, GABA system dysfunction, and schizophrenia. Biol Psychiatry. 2015;40:190-206.

113. Killcross S, Robbins TW, Everitt BJ. Different types of fearconditioned behaviour mediated by separate nuclei within amygdala. Nature. 1997;388:377-380.

114. Bzdok D, Laird AR, Zilles K, Fox PT, Eickhoff SB. An investigation of the structural, connectional, and functional subspecialization in the human amygdala. Hum Brain Mapp. 2013;34:3247-3266.

115. Kerestes R, Chase HW, Phillips ML, Ladouceur CD, Eickhoff SB. Multimodal evaluation of the amygdala's functional connectivity. Neuroimage. 2015;148:219-229.

116. Hortensius R, Terburg D, Morgan B, Stein DJ, van Honk J, de Gelder B. The role of the basolateral amygdala in the perception of faces in natural contexts. Philos Trans R Soc B Biol Sci. 2016;371:20150376.

117. Harrison PJ. On the neuropathology of schizophrenia and its dementia: neurodevelopmental, neurodegenerative, or both? Neurodegeneration. 1995;4:1-12.

118. Burda JE, Sofroniew MV. Reactive gliosis and the multicellular response to CNS damage and disease. Neuron. 2014;81:229-248.

119. Cotter DR, Pariante CM, Everall IP. Glial cell abnormalities in major psychiatric disorders: Th evidence and implications. Brain Res Bull. 2001;55:585-595.

120. de la Torre-Ubieta L, Won H, Stein JL, Geschwind DH. Advancing the understanding of autism disease mechanisms through genetics. Nat Med. 2016;22:345-61.

121. Marín O. Developmental timing and critical windows for the treatment of psychiatric disorders. Nat Med. 2016;22:1229-1238.

122. Birnbaum R, Weinberger DR. Genetic insights into the neurodevelopmental origins of schizophrenia. Nat Rev Neurosci. 2017; 18:727-740.

123. Gandal MJ, Haney JR, Parikshak NN, Leppa V, Ramaswami G, Hartl C. Shared molecular neuropathology across major psychiatric disorders parallels polygenic overlap. Science. 2018;359:693-697.

124. Mühleisen TW, Reinbold CS, Forstner AJ, Abramova LI, Alda M, Babadjanova $G$, et al. Gene set enrichment analysis and expression pattern exploration implicate an involvement of neurodevelopmental processes in bipolar disorder. J Affect Disord. 2018;228:20-25.

125. Hanford LC, Nazarov A, Hall GB, Sassi RB. Cortical thickness in bipolar disorder: a systematic review. Bipolar Disord. 2016;18:4-18.

126. Haukvik UK, Westlye LT, Mørch-Johnsen L, Jørgensen KN, Lange EH, Dale AM. In vivo hippocampal subfield volumes in schizophrenia and bipolar disorder. Biol Psychiatry. 2015;77:581-8.

127. Weinberger DR, Radulescu E. Finding the elusive psychiatric "lesion" with 21 st-Century neuroanatomy: a note of caution. Am J Psychiatry. 2016;173:27-33.

128. Bearden CE, Thompson PM, Dalwani M, Hayashi KM, Lee AD, Nicoletti M. Greater cortical gray matter density in lithium- 
treated patients with bipolar disorder. Biol Psychiatry. 2007;62:7-16

129. Cousins DA, Aribisala B, Nicol Ferrier I, Blamire AM. Lithium, gray matter, and magnetic resonance imaging signal. Biol Psychiatry. 2013;73:652-7.

130. Owen MJ. New approaches to psychiatric diagnostic classification. Neuron. 2014;84:564-71.

131. Lawrie SM, O’Donovan MC, Saks E, Burns T, Lieberman JA. Towards diagnostic markers for the psychoses. Lancet Psychiatry. 2016;3:375-85.

132. Kleinman JE, Law AJ, Lipska BK, Hyde TM, Ellis JK, Harrison PJ, et al. Genetic neuropathology of schizophrenia: new approaches to an old question and new uses for postmortem human brains. Biol Psychiatry. 2011;69:140-5.

133. Jaffe AE. Postmortem human brain genomics in neuropsychiatric disorders--how far can we go? Curr Opin Neurobiol. 2016;36:107-11.

134. Deep-Soboslay A, Iglesias B, Hyde TM, Bigelow LB, Imamovic $\mathrm{V}$, Herman MM, et al. Evaluation of tissue collection for postmortem studies of bipolar disorder. Bipolar Disord. 2008;10:822-8.

135. Harrison PJ. The neuropathological effects of antipsychotic drugs. Schizophr Res. 1999;40:87-99.

136. Konopaske GT, Dorph-Petersen KA, Sweet RA, Pierri JN, Zhang W, Sampson AR, et al. Effect of chronic antipsychotic exposure on astrocyte and oligodendrocyte numbers in macaque monkeys. Biol Psychiatry. 2008;63:759-765.
137. Boldrini M, Underwood MD, Hen R, Rosoklija GB, Dwork AJ, Mann JJ, et al. Antidepressants increase neural progenitor cells in the human hippocampus. Neuropsychopharmacol. 2009;34:2376-2389.

138. Cotel MC, Lenartowicz EM, Natesaon S, Modo MM, Cooper JD, Williams SCR, et al. Microglial activation in the rat brain following chronic antipsychotic treatment at clinically relevant doses. Eur Neuropsychopharmacol. 2015;25:2098-2107.

139. Rajkowska G, Clarke G, Mahajan G, Licht CMM, van de Werd $\mathrm{H}$, Yuan P, et al. Differential effect of lithium on cell number in the hippocampus and prefrontal cortex in adult mice: a stereological study. Bipolar Disord. 2016;18:41-51.

140. Benes FM, Lange N. Two-dimensional versus three-dimensional cell counting: a practical perspective. Trends Neurosci. 2001;24:11-7.

141. Dorph-Petersen KA, Lewis DA. Stereological approaches to identifying neuropathology in psychosis. Biol Psychiatry. 2011;69:113-26.

142. Tao R, Cousijn H, Jaffe AE, Burnet PW, Edwards F, Eastwood $\mathrm{SL}$, et al. Expression of ZNF804A in human brain and alterations in schizophrenia, bipolar disorder, and major depressive disorder: a novel transcript fetally regulated by the psychosis risk variantrs1344706. JAMA Psychiatry. 2014;71:1112-20.

143. Fromer M, Pocklington AJ, Kavanagh DH, Williams HJ, Dwyer $\mathrm{S}$, Gormley $\mathrm{P}$, et al. De novo mutations in schizophrenia implicate synaptic networks. Nature. 2014;506:179-84. 